Check for updates

Cite this: RSC Adv., 2017, 7, 38604

\title{
Development of sustainable bio-adhesives for engineered wood panels - A Review
}

\author{
Venla Hemmilä, ${ }^{* a}$ Stergios Adamopoulos, (D) *a Olov Karlsson ${ }^{\text {b }}$ and Anuj Kumar (iD ${ }^{a}$ \\ Changes in both formaldehyde legislations and voluntary requirements (e.g. Germany RAL) are currently the \\ driving factors behind research on alternatives to amino-based adhesives; moreover, consumer interest in \\ healthy and sustainable products is increasing in bio-based adhesives. Sources of formaldehyde emissions \\ in wood-based panels as well as different emission test methods have been discussed, and the main focus \\ of this review is on the research conducted on sustainable bio-based adhesive systems for wood panels. \\ Lignin, tannin, protein, and starch have been evaluated as both raw materials and adhesive alternatives to \\ existing amino-based thermosetting adhesives. Adhesion improving modifications of these bio-based \\ raw materials as well as the available and experimental crosslinkers have also been taken into account.
}

Received 13th June 2017

Accepted 22nd July 2017

DOI: $10.1039 / \mathrm{c} 7 \mathrm{ra06598a}$

rsc.li/rsc-advances

are additional crucial parameters the new, bio-based adhesives

\section{Introduction}

The wood panel industry uses almost exclusively synthetic, petroleum-derived thermosetting adhesives, which are mainly based on the reaction of formaldehyde with urea, melamine, phenol, or co-condensates. ${ }^{1}$ The low-cost and good adjustable properties of these adhesives have made it difficult for new biobased alternatives (e.g. lignin, tannin, starch, protein) to enter this market. Sustainable adhesives should not only be available at low costs, but also need to be easily distributable, fast reacting, and have a long pot life. ${ }^{1}$ The mechanical strength of manufactured panels and especially their moisture tolerance

a Department of Forestry and Wood Technology, Linnaeus University, Lückligs Plats 1, 35195 Växjö, Sweden. E-mail:venla.hemmila@lnu.se; stergios.adamopoulos@lnu.se; Tel: +46470767547

${ }^{b}$ Wood Technology, TVM, Luleå University of Technology, 93187 Skellefteå, Sweden have yet to fulfil satisfactorily. ${ }^{2}$

There are two main factors driving the trend to move away from using formaldehyde-based synthetic resins for woodbased panel manufacturing: formaldehyde emissions and sustainability of raw materials and final products. In the panel industry, sustainability and petroleum independency cannot, as of yet, justify the increase in cost due to new bio-based adhesives. Thus, concern about formaldehyde emissions from panels, especially in indoor applications, is currently the most important driving factor. ${ }^{3}$ Legislations concerning both work environment and final product emissions have steadily become stricter over time. In 2004, the International Agency for Research on Cancer (IARC) re-classified formaldehyde from "probable human carcinogen" to "known human carcinogen". ${ }^{4}$ The California Air Resources Board (CARB) also formulated regulations with new limits for formaldehyde emissions from composite wood products. ${ }^{5}$ It is unclear how the limits of

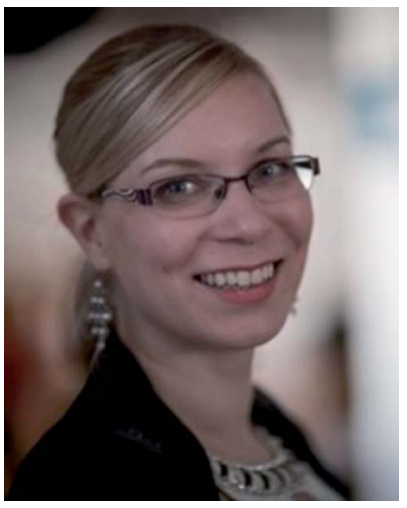

Venla Hemmilä is an industrial $P h D$ student researching lignin adhesive systems and developing crosslinkers for them. She is also employed by furniture manufacturer IKEA Industry $A B$ as project leader for projects related to adhesive development, quality, and formaldehyde emissions.

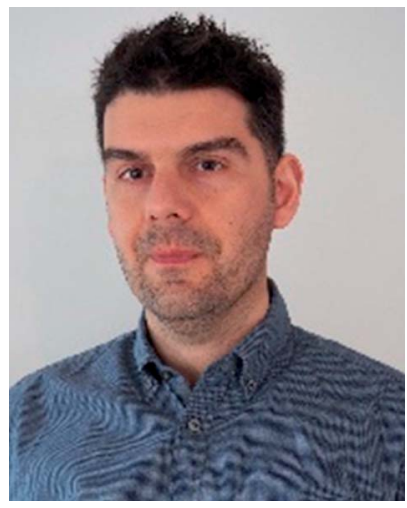

Stergios Adamopoulos is a Professor in Forest Products at the Department of Forestry and Wood Technology, Linnaeus University, Sweden. His academic career started in 1996 by working at different universities and research institutes in Greece, Spain and Germany. His research interests are related to forest utilisation, wood quality, wood protection and modification, recovery of biomaterials, and wood and fibre products. 
formaldehyde emissions for wood panels will change in different parts of the world in the future. The wood-based panel industry has so far reacted by applying appropriate formaldehyde scavengers (catchers) by developing low-emission melamine fortified urea-formaldehyde (MUF) adhesives and by employing other synthetic or bio-based adhesives that do not contain formaldehyde.

As a volatile organic compound (VOC), most of the formaldehyde is normally emitted from panels during production. There are two formaldehyde sources when producing wood panels: formaldehyde that might be contained in the adhesive and that in the wood material itself. The emissions can be reduced by either using formaldehyde scavengers or by decreasing free formaldehyde in the adhesive and number of formaldehyde emitting groups during and after curing (e.g. reducing formaldehyde/urea molar ratio). ${ }^{2}$ The most typical scavenger for wood-based panels is urea, but other compounds like ammonia and ammonium salts can also be used. ${ }^{6}$ They can be added directly to the synthetic resin or wood particles. Some organic scavengers, such as tannin powder, wheat flour and charcoal have also been shown to reduce formaldehyde emissions. ${ }^{7}$ By loading urea onto the nano-mesoporous structure of an inorganic additive (diatomaceous earth), an improved scavenging function of urea has been shown. ${ }^{8}$ Additionally, various types of carbon based nanomaterials such as activated nanocarbon, carbon nanotubes, exfoliated graphite nanoparticles are used as formaldehyde adsorbents in formaldehyde-based adhesives. ${ }^{9-12}$

Synthetic diphenylmethane diisocyanates (MDIs) offer non-formaldehyde emitting solutions for panel producers. The most commonly used MDI for panel production is polymeric MDI (pMDI). The produced panels have better mechanical (i.e. stiffness) and physical (resistance towards humidity) properties. ${ }^{2}$ In North America, MDIs are commonly used for construction panels (oriented strand board, OSB) and to some extent for other panel types such as particleboards (PBs), high density fibreboards (HDFs) and medium density fibreboards (MDFs). Using MDIs for these boards is possible because their cost, with reduced application amounts, is comparable to that of melamine fortified ureaformaldehyde adhesives (MUFs). However, in Europe, prices for MDIs exceed those for UFs and MUFs. Also, extra safety control is required due to toxicity of isocyanate during production. This makes transition to the use of MDIs slower and is thus more difficult to implement on a large scale in Europe. Except for lower adhesive amounts, MDIs offer no clear advantage with respect to sustainability or environmental friendliness in panel products.

"Bio-based product" is defined as "a commercial or industrial product (other than food or feed) that is composed, in whole or in significant part, of biological products or renewable domestic agricultural materials (including plant, animal, and marine materials) or forestry materials". ${ }^{13}$ Only a few bio-based industrial adhesive products exist for panels, and these have a high cost. They can be used to produce premium priced panels, but so far, they are not economically feasible for mainstream panel production. For these adhesives and for the ones still in development, a synthetic cross-linker is usually required to reach the required properties at reasonable cost. Soy protein is among the first bio-based adhesives to be launched commercially for plywood manufacturing, and the most promising research is around different kinds of proteins. ${ }^{\mathbf{1 4}}$ Although in limited capacity, industrial applications also exist for panel adhesives based on tannin and starch. Lignin-based adhesives are also of interest as new types of bio-refineries increasingly bring new types of lignin to the market.

This article presents a review of the research undertaken on various bio-based adhesive systems usable for wood panels as

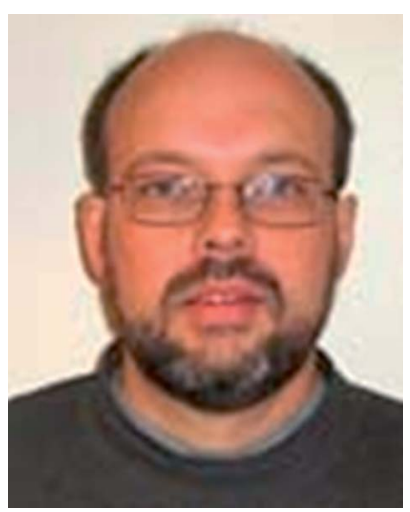

Olov Karlsson is working as an Associate Professor at Wood Science and Engineering Division at Luleå University of Technology in Skellefteå, Sweden. Fields of interest: Solid wood chemistry and improvement of wood properties. Ph.D thesis 1998 (KTH Stockholm): Studies on the extent of bonding between lignin and polysaccharides in pulps.

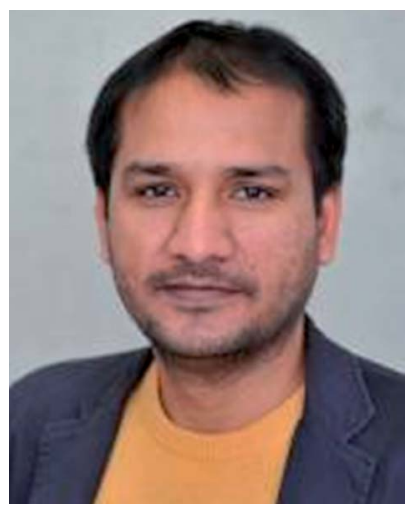

Anuj Kumar is a postdoctoral researcher at Department of Forestry and Wood Technology, Linnaeus University, Sweden. The main interests of his research are polymeric biomaterials, adhesives, coatings, biobased building materials, wood composites, wood modification and nanocomposites. He worked as a postdoctoral researcher at Department of Building Structures, Faculty of Civil Engineering, Czech Technical University in Prague and visiting scientist at Fraunhofer Institute for Wood Research Wilhelm-KlauditzInstitut (WKI), Germany and University of Ljubljana, Slovenia. He received his $P h D$ degree in Chemical Engineering from the Universiti Malaysia Pahang (Malaysia) and Master's degree in Wood Science and Technology from Forest Research Institute University, Dehradun, India. 
Table 1 Some major renewable biopolymers, their sources and principal industrial uses (reproduced from ref. 15 with permission from Taylor $\&$ Francis)

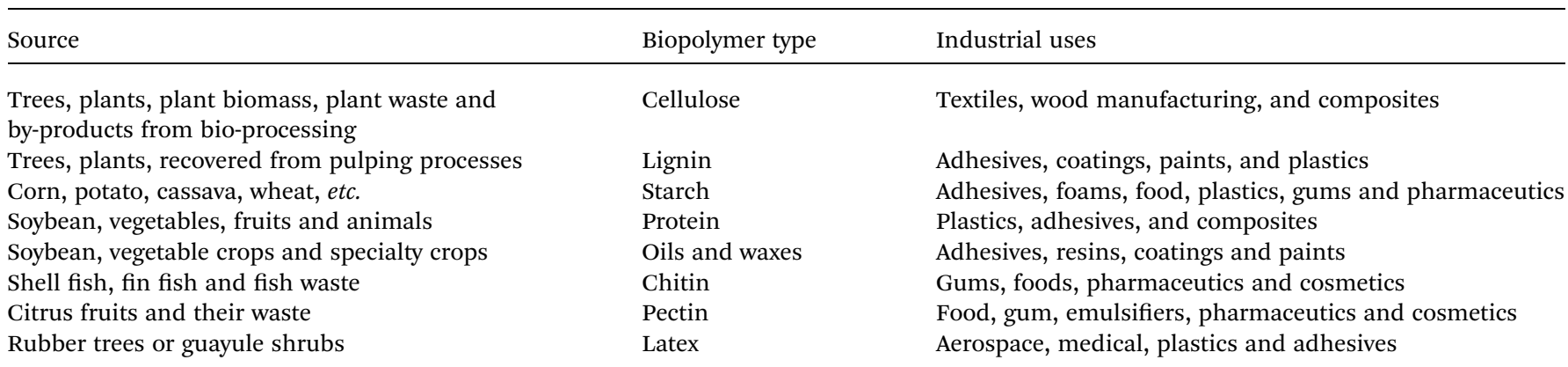

alternatives to existing amino-based thermosetting adhesives. The first part focuses on the structure and availability of different sustainable raw materials that can be used to formulate adhesives, such as lignin, starch, protein and tannin, as presented in Table $1 .^{15}$ The second part focuses on the suitability of these raw materials as adhesives. Bio-based adhesives tested on veneer and solid wood are included, as this testing approach is quite common in the initial stages of wood-based panel adhesive development. Future prospects of promising adhesives for the wood-based panel industry are also given,

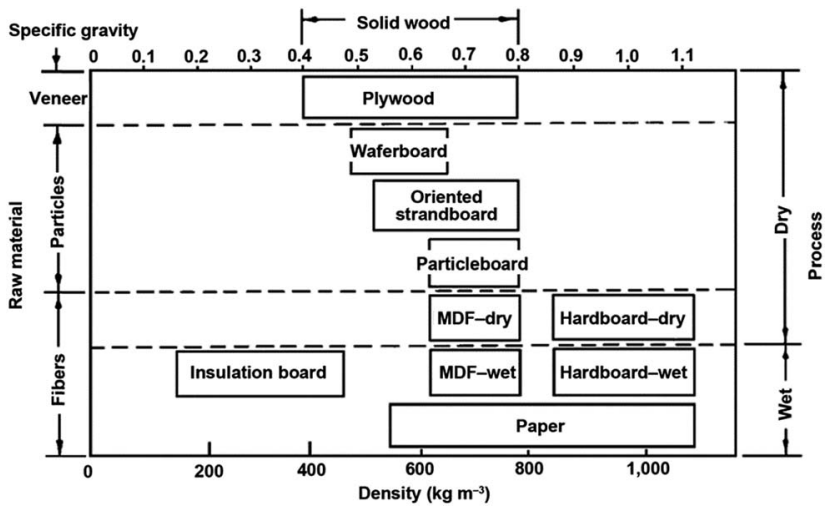

Fig. 1 Classification of wood-based panels. ${ }^{17}$ taking into account recent opportunities and challenges caused by emerging bio-refineries and food shortage policies.

\section{Wood-based panels (WBPs) and adhesives}

Wood-based panels (WBPs) are composite products manufactured by effective bonding of wood materials (fibers, flakes, particles, chips, wood powder, veneers, etc.) with various adhesives. WBPs are classified by usage for structural or nonstructural panels, to the exterior or interior grade panels, and by the type of wood and materials used ranging from fiberboards to laminated beams. Maloney $(1977)^{\mathbf{1 6}}$ classifies WBPs according to the type of raw materials used and process of manufacturing (dry and wet). Further, he proposes the division of panels according to their density and specific gravity, as shown in Fig. 1.

Urea-formaldehyde (UF) resins are extensively used as adhesives in the production of WBPs like medium density fiberboards (MDFs), particleboards and plywood. MDFs and particleboards consume $68 \%$ of UF resins produced in the world, while $23 \%$ is used in plywood manufacturing. Other types of adhesives predominantly used in the manufacturing of WBPs are phenol-formaldehyde (PF), melamine-urea-formaldehyde (MUF) and polymeric 4,4diphenylmethane diisocyanate (pMDI). These synthetic

Table 2 Advantages and disadvantages of synthetic adhesives used in manufacturing of WBPs 9

\begin{tabular}{llll}
\hline & Adhesives & & \\
\cline { 2 - 4 } Properties & UF & MUF & PF \\
\hline Price & Low & Medium to high & Medium \\
Cure temperature & Low & Medium & High \\
Pressing time & Short & Medium & Medium to long \\
Susceptibility against wood species & High & Medium & Medium \\
Efficiency & Low & Medium to high & Medium to high \\
Compatibility with bio-based raw-materials & Medium & Medium & Hedium to high \\
Manipulations & Easy & Easy & High \\
Resistant against hydrolysis & No & Medium to high & High \\
Use in wet conditions & No & Partially yes & Yes \\
Formaldehyde emission & E1. CRAB I possible & E1. CARB II ${ }^{5}$ possible & Very low emission
\end{tabular}


adhesives have certain advantages and disadvantages as mentioned in Table 2 .

\section{Formaldehyde emissions from WBPs}

WBPs and flooring materials are the main sources of formaldehyde emissions inside buildings. ${ }^{18}$ Various WBPs like particleboards, plywood, medium density fibreboards and high density fibreboards have become increasingly popular and are being used for manufacturing of furniture, cabinets and various building products. These products are mainly bonded with formaldehyde-based adhesives (UF, MUF and phenolformaldehyde), which are the primary sources of formaldehyde. UF resin has the highest formaldehyde emission rate because it contains a large amount of incompletely cured UF, which results in free formaldehyde after the hydrolysis of the cured UF resin. ${ }^{19}$ However, formaldehyde release can also be reduced by adding formaldehyde-binding substances ("scavengers") to the resin, such as formaldehyde-binding paraffin ${ }^{20}$ or by adding urea, propylamine, methylamine, ethylamine, and cyclopentylamine solution to the UF resin. ${ }^{20}$ It has been shown that within a certain range of molar ratios, there is an almost linear relationship between molar ratio, formaldehyde release and extractable formaldehyde content. A decrease in formaldehyde content in the resin leads to a decrease in formaldehyde emission rate in the finished product. ${ }^{21}$
Different factors are associated with formaldehyde and VOC emissions from WBPs. During particleboard production, formaldehyde emissions increase with pressing temperature and time, mat resin content and moisture content, and board density. ${ }^{22}$ It is also stated that VOCs increased with pressing temperature linearly. This increase in VOC emission is mainly due to the increase in emissions of terpenes and aldehydes. A linear relationship of formaldehyde emissions with pressing temperature also exists. ${ }^{23}$ Temperature and humidity can influence formaldehyde emissions from WBPs that are produced using UF-type adhesives. ${ }^{24}$ For example, when increasing the temperature from 25.2 to $50.6{ }^{\circ} \mathrm{C}$, the initial emittable formaldehyde from dry building materials is increased significantly by about $507 \% .^{25}$ In general, formaldehyde emissions from WBPs can be influenced by exogenous and endogenous factors. ${ }^{26}$ The exogenous factors include temperature, humidity, air movement over the panel surface, air change rate and local formaldehyde concentration within the space where the material is placed. The endogenous factors include wood species, moisture content of wood material, type and chemical composition of the adhesive binder used, additives (e.g. catalysts and formaldehyde scavengers), arrangement of multi-layer board, surface treatment, density of the board and manufacturing conditions (e.g. temperature and duration of the hot pressing process). ${ }^{27}$ There is a small amount of free formaldehyde in the liquid resin (generally less than $0.1 \%$ ), which is used during cross-linking of the resin. Free formaldehyde is present in various forms in the manufactured panel. It can react

Table 3 Comparison of standard methods for determination of formaldehyde emissions

\begin{tabular}{|c|c|c|c|c|c|c|}
\hline Region & Method & Size loading factor & $\begin{array}{l}\text { Edge sealing } \\
\left(\mathrm{m} \text { open edge } \mathrm{m}^{-2}\right)\end{array}$ & $\begin{array}{l}\text { Conditioning } \\
\text { Temp/RH }\end{array}$ & Temp/RH & Air exchange/hour \\
\hline \multirow[t]{3}{*}{ EU } & $\begin{array}{l}\text { EN } 717-10.225,1 \text { or }>12 \mathrm{~m}^{3} \\
\text { chamber }\end{array}$ & $1 \mathrm{~m}^{2} \mathrm{~m}^{-3}$ & Partly $\left(1.5 \mathrm{~m} \mathrm{~m}-^{2}\right)$ & $23{ }^{\circ} \mathrm{C} / 45 \%$ & $23{ }^{\circ} \mathrm{C} / 45 \%$ & 1 \\
\hline & $\begin{array}{l}\text { EN 717-2 gas analysis } 41 \\
\text { chamber }\end{array}$ & $0.4 \times 0.05 \mathrm{~m}$ & Yes & Not stated & $60^{\circ} \mathrm{C} / \leq 3 \%$ & 15 \\
\hline & EN 120 perforator & $0.025 \times 0.025 \mathrm{~m}, 110 \mathrm{~g}$ & No & Not stated & $\begin{array}{l}\text { Toluene } \\
\text { extraction } \\
\text { at } 110^{\circ} \mathrm{C}\end{array}$ & No \\
\hline \multirow[t]{3}{*}{ Japan } & JIS A $19010.1-1 \mathrm{~m}^{3}$ chamber & $2.2 \mathrm{~m}^{2} \mathrm{~m}^{-3}$ & Yes & $28{ }^{\circ} \mathrm{C} / 50 \%$ & $28{ }^{\circ} \mathrm{C} / 50 \%$ & 0.5 \\
\hline & JIS A 1469 9-111 desiccator & $0.18 \mathrm{~m}^{2}$ & No $\left(27 \mathrm{~m} \mathrm{~m}^{-2}\right)$ & $20{ }^{\circ} \mathrm{C} / 65 \%$ & $20{ }^{\circ} \mathrm{C} / 0-80 \%$ & No \\
\hline & JAS 233 9-111 desiccator & $0.18 \mathrm{~m}^{2}$ & No $\left(27 \mathrm{~m} \mathrm{~m}-^{2}\right)$ & No & & No \\
\hline \multirow[t]{4}{*}{ China } & GB 18580 perforator & $\begin{array}{l}0.020 \times 0.020 \mathrm{~m} \\
105-110 \mathrm{~g}\end{array}$ & No & Not stated & $\begin{array}{l}\text { Toluene } \\
\text { extraction } \\
\text { at } 110{ }^{\circ} \mathrm{C}\end{array}$ & No \\
\hline & GB 18580, 9-11 L desiccator & $\begin{array}{l}0.15 \times 0.05 \mathrm{~m} \\
10 \text { pieces }\end{array}$ & No & Not stated & $20^{\circ} \mathrm{C}$ & No \\
\hline & GB $18580,40 \mathrm{~L}$ desiccator & $0.045 \mathrm{~m}^{2}$ & Yes & $\begin{array}{l}20^{\circ} \mathrm{C} \text { in vinyl } \\
\text { resin bag }\end{array}$ & $20{ }^{\circ} \mathrm{C}$ & No \\
\hline & $\begin{array}{l}\text { GB } 18580,1 \mathrm{~m}^{3} \\
\text { environmental chamber }\end{array}$ & $1 \mathrm{~m}^{2} \mathrm{~m}^{-3}$ & Yes & Not stated & $23{ }^{\circ} \mathrm{C} / 45 \%$ & 1 \\
\hline
\end{tabular}


with moisture present in the wood to form methylene glycol, polymethylene glycol, polyoxymethylene hemiacetal, etc., and can undergo labile binding to the wood or to the polymer resin. ${ }^{27}$ Free formaldehyde will in time migrate and be released to the environment, especially under high temperature and when exposed to a well-ventilated environment. ${ }^{26}$ Table 3 provides an overview of the different international standards used for calculation/estimation of formaldehyde emissions.

European panel producers prefer the perforator method (EN $120)$ as a quality control method due to the very short testing time $(2.5 \mathrm{~h})$, cheap equipment, and available data. However, toluene used is a concern for the work environment and the correlation to chamber methods is poor $\left(R^{2}=0.8731\right){ }^{28,29}$ The perforator measures formaldehyde content, while most legislations focus on emissions. Desiccator (JIS A 1469, JAS 233, GB 18580) is an emission method with cheap equipment, but the testing time is longer ( $24 \mathrm{~h}$ testing and seven days preconditioning). Flask method is another quick and inexpensive emission measurement method, but accuracy and correlation to the chamber methods are difficult to achieve due to small sample sizes, no air exchange, and high relative humidity (correlation to $1 \mathrm{~m}^{3}$ chamber is $R^{2}=$ 0.67). Gas analysis method (EN 717-2) is an accelerated emission test method with relatively short testing time $(4 \mathrm{~h})$. The high temperature and air exchange rate cause variations with respect to chamber methods, and it is not officially approved for uncoated board materials (PBs, OSBs, MDFs). The correlation to the $1 \mathrm{~m}^{3}$ chamber method is however still better than that of the methods mentioned above $\left(R^{2}=0.859\right)$. Chamber methods (EN 717-1, ASTM D 6007, ASTM E 1333, JIS A 1901, GB 18580) have the benefit of mimicking final use conditions for furniture. The bigger sample size also helps against errors caused by variations in material. However, they are expensive and have long testing times (test period 10-28 days), making them unsuitable for factory quality control. It should be noted that variables between test methods stated in Table 3 can lead to significant differences between chamber test methods. ${ }^{27}$

\section{Sustainable resources for adhesives for WBPs}

\subsection{Lignin}

Historically, most of the available lignin comes as a by-product of the pulping process. These lignin derived fragments have low value and usually serve as fuel for the recovery boiler of pulp and paper mills. They are very heterogeneous in their structure with structural units that range from almost native to highly degraded..$^{30}$ The structure of lignin plays a key role in the required modifications and crosslinking to allow for better adhesive properties of the derived adhesive. Commercial lignin types from different processes are divided into two main categories (Fig. 2). Sulfur containing lignin (mainly kraft lignin found in the black liquor of kraft pulping process and lignosulfonate lignin in the sulphite liquor of sulfite pulping process) and non-sulfur biorefinery lignin (soda, organosolv, steam explosion, hydrolysis, diluted acid, pyrolytic, high-pressure refining, ammonia-fiber-expansion lignin, etc.). ${ }^{31,32}$ The main

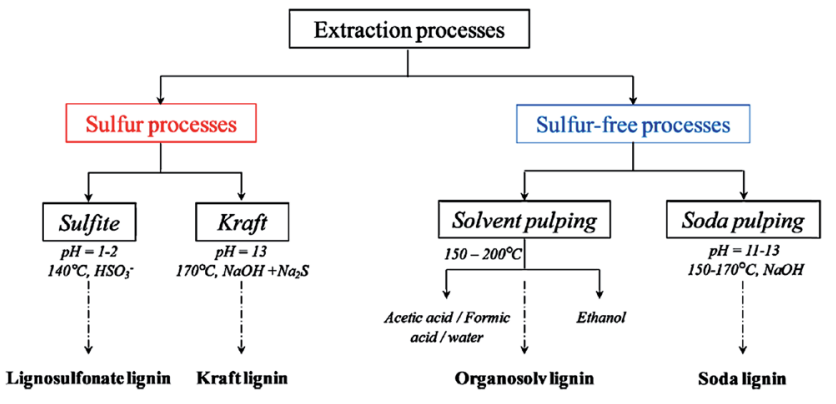

Fig. 2 Different extraction processes to separate lignin from lignocellulosic biomass and corresponding productions of technical lignin (reproduced from ref. 33 with permission from Elsevier Ltd).

chemical changes occurring during processing of kraft lignin, soda lignin and ethanol/water process lignin are demonstrated in Fig. 3.

Lignin is composed of cross-linked phenolic $\mathrm{C}_{6} \mathrm{C}_{3}$ units. The main repeating units are presented in Fig. $4 .^{35}$ The major chemical functional groups in lignin include hydroxyl, methoxyl, carbonyl and carboxyl groups. Methods used for identification of the chemical groups in lignin include Fourier transform infrared (FTIR) and UV/vis spectroscopy, pyrolysisGC/MS, liquid chromatography, elemental analysis, and wet chemistry methods, such as thioacidolysis, methoxyl content analysis and nitrobenzene oxidations. ${ }^{36-38}{ }^{1} \mathrm{H}^{13} \mathrm{C}$ correlation 2D NMR spectroscopy techniques are often used instead of 1D NMR, due to overlapping signals of irregular lignin structures with carbohydrate, cellulose, and protein impurities often found in residual lignin.

There is a big difference in properties and water solubility of lignin derived from different processes. Lignin residue from sulfur-free extraction processes, such as all alkaline processes, is typically of relatively high quality. It has higher amounts of functional groups than sulfur lignin as the treatments are milder. ${ }^{39,40}$ However, detailed structural information is still missing for most types of biorefinery lignin. The suitability of a lignin type for incorporation into phenolic adhesives is partly defined by the presence of chemical features that can be involved in polymerization reactions; the two most important being the phenolic hydroxyl and aliphatic hydroxyl groups. Phenolic hydroxyl groups increase the reactivity of lignin towards formaldehyde due to activation of the aromatic ring in $o$-position and provide the possibility to form quinone methide intermediates, which could be a starting point for further condensation with other phenolic units. ${ }^{39,41}$ Kraft lignin is water-insoluble and mostly solvent-insoluble except for in highly alkaline environments $(\mathrm{pH}>11)$. Soda lignin and organosolv lignin are also essentially water-insoluble, while lignosulphonates are water-soluble in the presence of a suitable counter ion. ${ }^{42,43}$ Biorefinery lignin is expected to be available in larger amounts in the future as a result of the growth in biomass-to-biofuel and biomass-to-sugar conversion industries. Oxidative ways of turning biorefinery lignin into valuable platform chemicals, which can later be turned into adhesives, has been reviewed by Ma et al. (2015). ${ }^{44}$ 

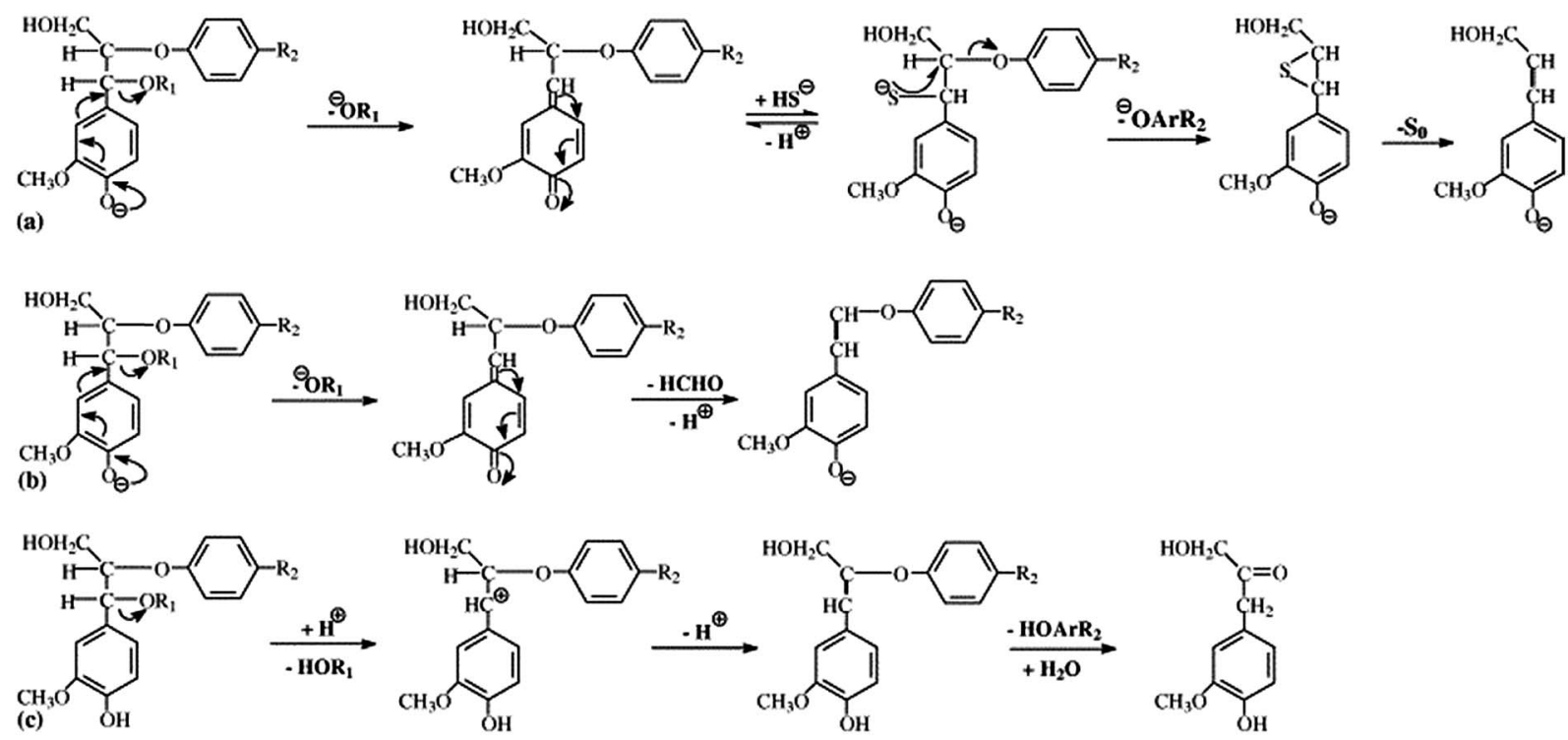

Fig. 3 Schematic representation of the main changes occurring in lignin structure during the (a) kraft, (b) soda and (c) ethanol/water processes (reproduced from ref. 34 with permission from Elsevier Ltd).

\subsection{Tannins}

Tannins occur naturally in bark, wood, leaves and fruits of plants. Tannins are used in various industrial applications, mainly in the manufacturing of inks, textile dyes and as a corrosion inhibitor. Although tannin occurs in many plant species, only a few have high enough concentration to make its extraction worthwhile. Tannin can, for example, be extracted from pine, quebracho, oak, chestnut, wattle, eucalyptus, myrtle, maple, birch and willow. ${ }^{46}$ Different extraction methods are used, the most common ones being maceration, Soxhlet extraction supercritical $\mathrm{CO}_{2}$ and percolation. Other rare techniques such as microwave and ultrasound assisted extraction has also been studied to increase tannin yield. ${ }^{47}$ The extraction method affects adhesive properties of tannin extracts. The extraction agent affects degree of polymerization, sugar concentration and number of functional groups (e.g. hydroxyl groups). ${ }^{48,49}$ In the extraction solution, other components such as starch, polymeric carbohydrates and amino acids are also present. Purification steps to remove other components are typically not performed at an industrial scale, and tannin is typically sold as spray dried powders. ${ }^{1}$

Characterization of plant tannin is done by using matrixassisted laser desorption/ionization time-of-flight (MALDITOF), FTIR spectroscopy and nuclear magnetic resonance (NMR) spectroscopy. ${ }^{49}$ Tannins are loosely divided into two main categories based on their phenolic nature: condensed and hydrolysable tannins (Fig. 5). ${ }^{50}$

Condensed tannins, as their name suggests, possess a condensed and complex chemical structure made of hydroxylated C-15 flavonoid units with variations in the sites at which bonds between flavonoid units are formed. In the basic structure of condensed tannin, the A-ring can be of a resorcinol or phloroglucinol type and the B-ring of pyrogallol, catechol or sometimes phenol type. Catechol is the only B-ring structure capable of cross-linking. Phloroglucinol tannin type is obtained in low yields during extraction of most pines and has higher reactivity than resorcinol type towards formaldehyde, leading to short pot lives. Condensed tannins with a low degree of polymerization are soluble in polar solvents, and those with high degree of polymerization are soluble in dilute alkali solutions. ${ }^{51}$ Certain condensed tannins, such as from quebracho and wattle, are produced commercially from wood and bark and have been used to make wood adhesives since the 1970s. The polycyclic structure of condensed tannins leads to fast curing rates but also to high viscosity of adhesives. ${ }^{1}$

Hydrolysable tannins, as well as gallotannins and ellagitannins, are esters of carboxylic acids and sugars. Gallotannins are polymeric esters of gallic acid and normally associated with sugars. However, a study by Pizzi et al. ${ }^{52}$ shows that some of them do have an extensive polymeric structure based on pentagalloyl glucose repeating units. Hydrolysable tannins are readily soluble in water and easily hydrolyzed, resulting in benzoic acid derivates and sugars. In the natural state, hydrolysable tannins allow a low level of phenol substitution and have low nucleophilicity.

\subsection{Proteins}

The most common source of proteins is the mechanical or solvent extraction of oils, soy, palm, canola, cottonseed and sunflower oils making up the biggest markets. In Europe, protein from wheat gluten is also widely available as a byproduct from bioethanol production..$^{53}$ Other sources of proteins are zein from maize seeds, ${ }^{54}$ casein from milk and animal blood and feather. Soybeans are the largest single source of edible oil and account for approximately $52 \%$ of the total oil seed production in the world, USA and Brazil accounting for most of it. Soybean seed processing includes cleaning, drying, cracking, de-hulling, flaking and extraction of oil by using 


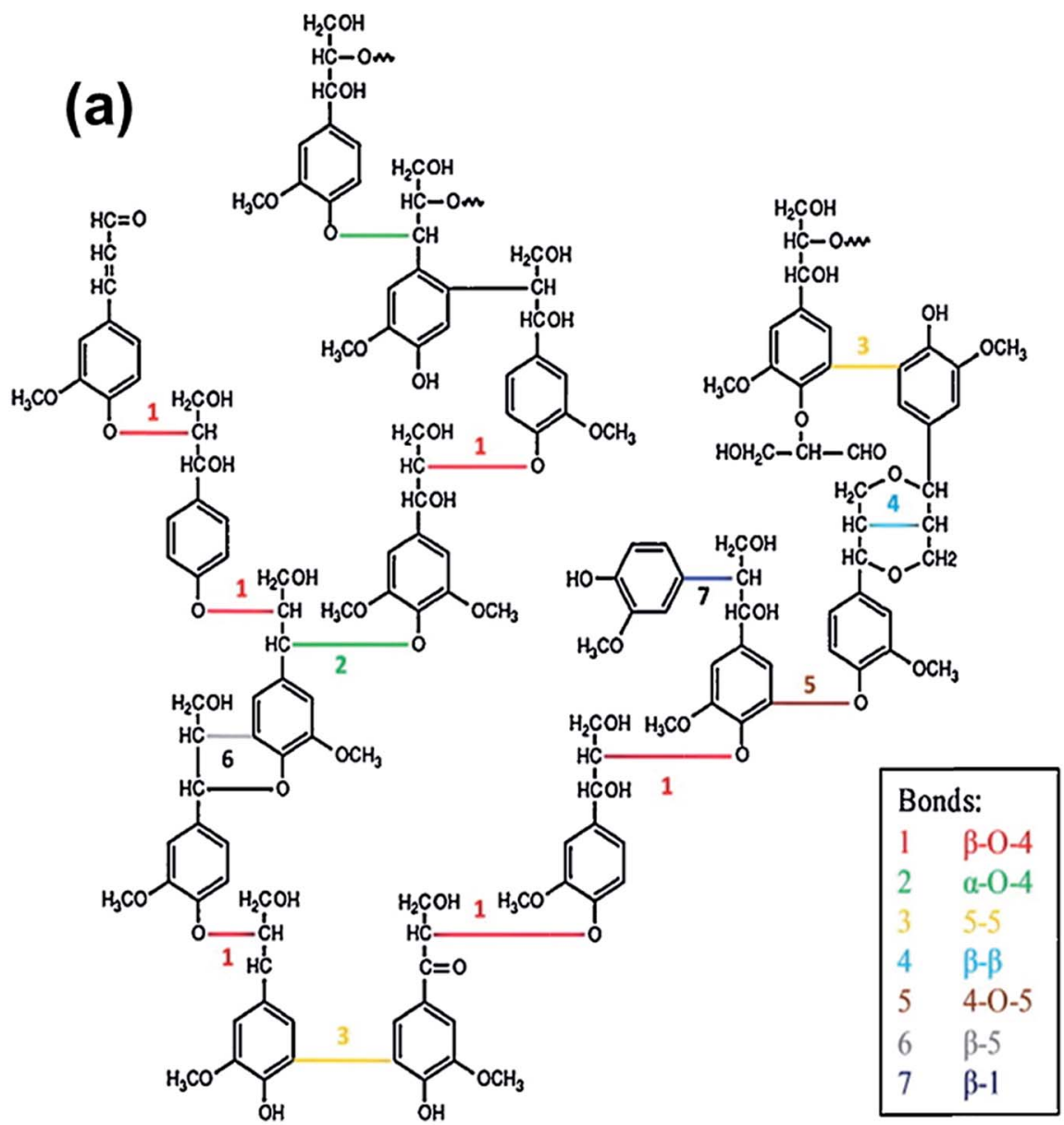

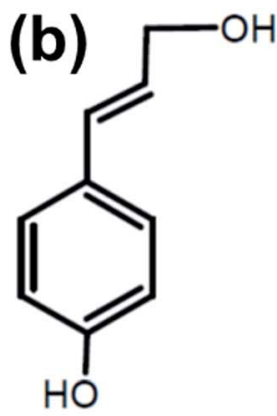

p-coumaryl alcohol

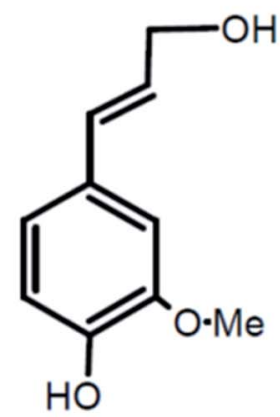

Coniferyl alcohol

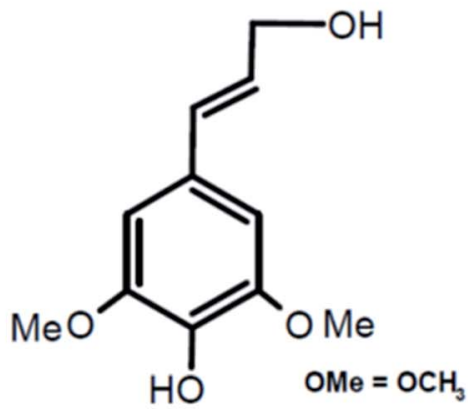

Sinapyl alcohol

Fig. 4 Main linkage of softwood lignin (a) (reproduced from ref. 45 with permission from Elsevier Ltd) and structural units of lignin (b).

hexane. Around 4.5 tons of soybean meal is produced for each ton of crude soybean oil. The protein content of this soybean meal is around $44-50 \%$, which is typically higher than that of the oil. ${ }^{55}$ The residual soybean meal is used for production of soy flour (SF), soy protein concentrates and soy protein isolates (SPI). Soy flour is the cheapest option but also the one with the lowest protein content. The most commonly produced isolates have a protein content of $80-90 \%$. Protein content greatly affects the properties of the final adhesive. The adhesive performance of soybean proteins is also affected by particle size, nature of the surface, structure of the protein, viscosity and pH. ${ }^{56}$ The high viscosity of soybean proteins results from increased intermolecular interactions due to uncoiling of molecules. Ionic environments weaken these electrostatic interactions, so treatment with salts or reducing agents can reduce viscosity without affecting adhesive strength. Other ways to reduce viscosity include enzymatic or alkaline hydrolysis. High $\mathrm{pH}$ increases rate of hydrolysis and consequently increases adhesive strength and water resistance, but shortens pot life. The optimal viscosity of the binder varies according to material to be glued..$^{57}$

Proteins are complex macromolecules consisting of amino acid monomers, which are chemically linked together to form polypeptide chains. The chemical links are mainly amide bonds 
a)

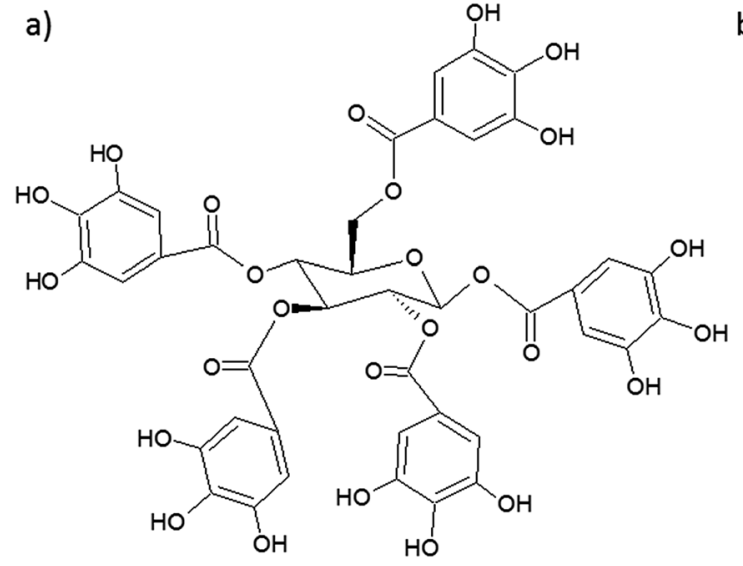

b)

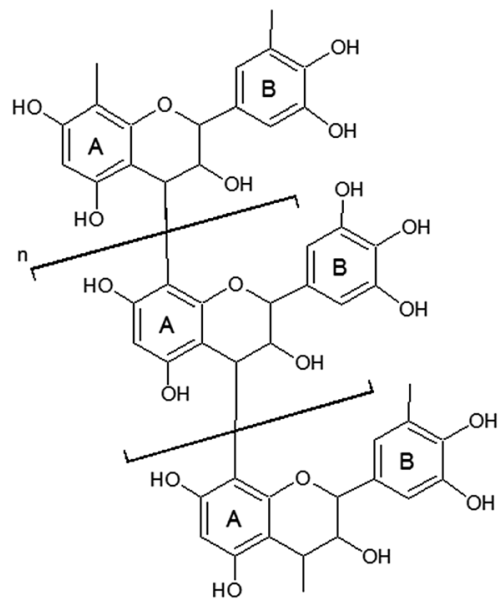

Fig. 5 (a) Hydrolysable tannin (the simplest one with gallic acid groups esterified to glucose) and (b) condensed tannin.

that are stable but can be degraded using strong acids. Proteins have a secondary structure of $\alpha$-helices and $\beta$-sheets and a threedimensional tertiary structure where $\alpha$-helices and $\beta$-sheets fold into compact globules that interact with the surfaces of other globules, forming a quaternary structure (Fig. 6). Physical and chemical properties of proteins are influenced by this complex structure as well as the order and presence of amino acids, as shown in Fig. 7.

The structure of protein molecules can be determined using methods such as crystallography, nuclear magnetic resonance (NMR) and infrared spectroscopy (IR). Besides these, methods such as atomic force microscopy (AFM) have shown to provide valuable information on the structure of modified proteins. ${ }^{53,58}$

Soy protein is a combination of about 18 different amino acids that include functional groups such as $-\mathrm{OH},-\mathrm{NH}_{2}$, $-\mathrm{COOH}$ and $-\mathrm{SH}$. Each one of these functionalities are polar in

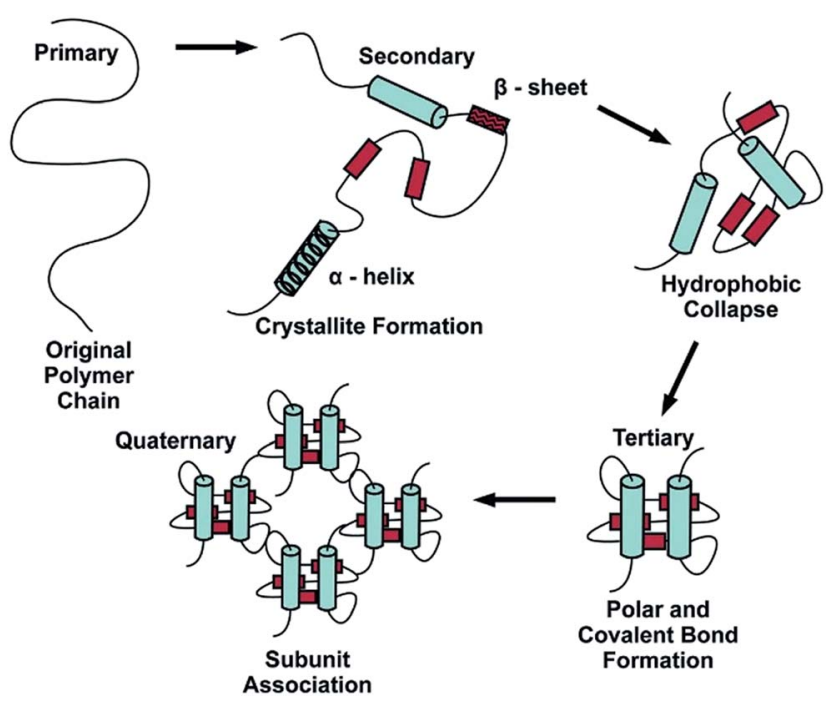

Fig. 6 Folding of protein (reproduced from ref. 56 with permission from American Chemical Society). nature, which leads to water sensitivity of soy proteins. The major components of soy protein are $7 \mathrm{~S}$ globulin ( $\beta$-conglycinin) and 11S globulin (glycinin), and minor factions $2 \mathrm{~S}$ and 15S. S stands for Svedberg unit that describes sedimentation rate. The effect of the ratio of $7 \mathrm{~S}$ and $11 \mathrm{~S}$ has been studied previously for physicochemical properties of soy protein adhesives. Hydration capacity is found to be better for systems with more $7 \mathrm{~S} .{ }^{59}$ The water solubility of soy protein is affected by $\mathrm{pH}$. The minimum solubility is at $\mathrm{pH} 4.2-4.6$, which is the isoelectric region of soy proteins taken as a whole..$^{57}$ At the isoelectric point, the concentration of the ammonium ion $\left(\mathrm{NH}_{3}{ }^{+-}\right.$ $\mathrm{CHRCOOH})$ equals that of the carboxylate ion $\left(\mathrm{NH}_{2} \mathrm{CHRCOO}^{-}\right)$ in the amino acids. Zein, the main storage protein of maize, on the other hand, has a high percentage of non-polar amino acids (leucine, alanine and proline), making it one of the few hydrophobic water-insoluble biopolymers. ${ }^{54}$

Although soybean protein is the most widely studied protein for use in wood adhesives, partly due to support from American United Soybean Board, other proteins have shown interesting qualities for wood bonding. The properties of other proteins, such as canola, wheat gluten, zein, casein, pea, mussel, whey and cottonseed can differ greatly due to the different composition of amino acid groups. This different composition can give adhesives produced with their unique properties such as the higher water tolerance of mussel proteins. ${ }^{60}$ Due to the high cost of mussel adhesives as compared to other wood adhesives, other approaches have been taken. As an example, soy proteins have been modified to resemble mussel proteins to increase moisture tolerance. ${ }^{61}$

The basic structure and denaturation mechanism of other proteins are similar to that of natural soy protein, although reaction to denaturation chemicals can vary among proteins. Wheat gluten is readily available as the by-product of starch production for bio-ethanol. It is also extracted from wheat flour to produce gluten-free products. Gluten is mainly used in the bakery industry. Wheat gluten is a hydrophobic protein due to its high amount of non-polar amino acids. Its isoelectric point is 7.3, and it is dispersible in alkali and acid but not in water. 


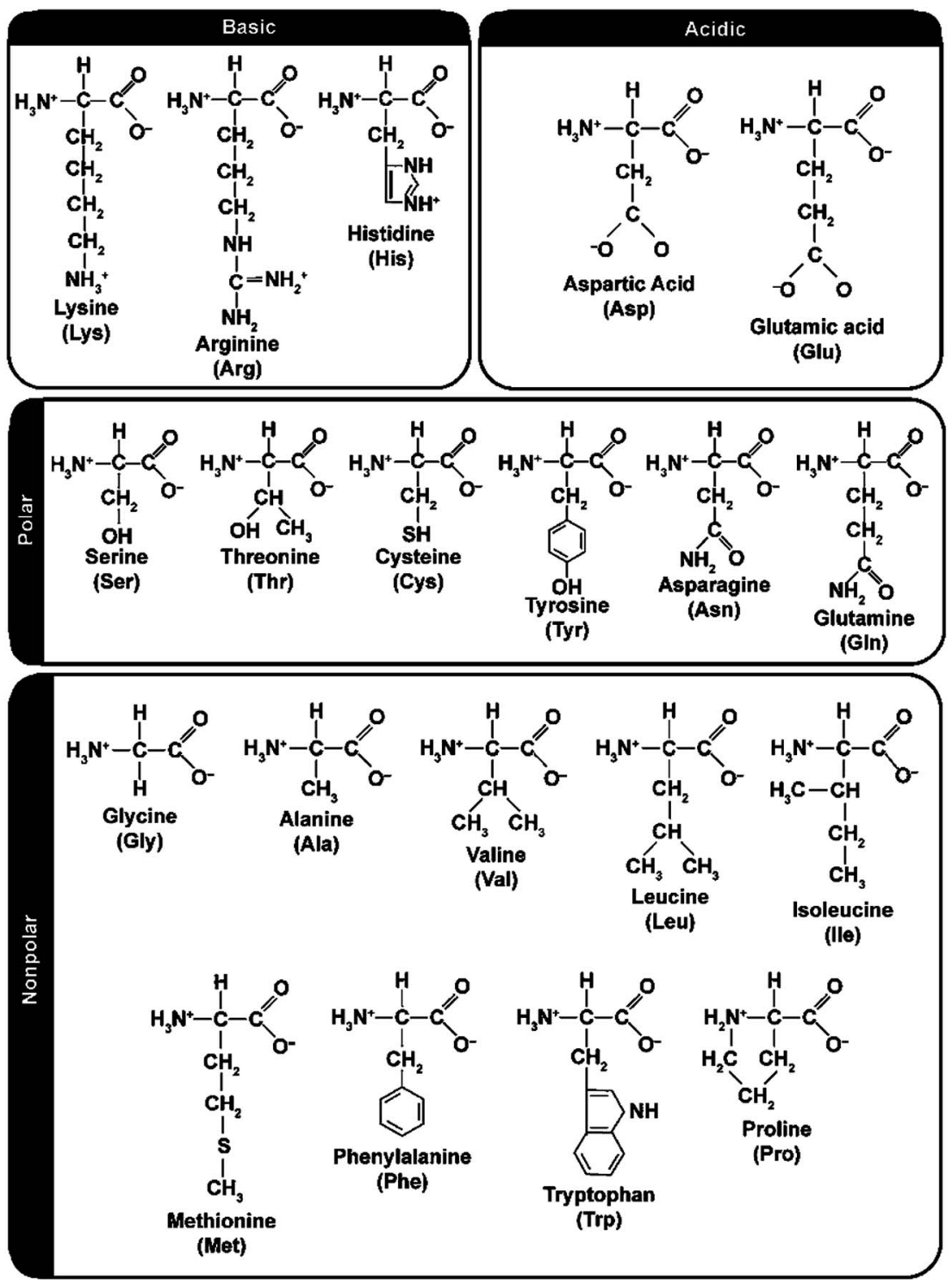

Fig. 7 Amino acids grouped as hydrophobic, hydrophilic or polar vs. non-polar as well as acidic or basic. (reproduced from ref. 56 with permission from American Chemical Society).

Wheat gluten consists mainly of storage protein that can be divided into two groups: glutenin (elastic properties) and gliadin (viscous properties), the former being dispersible in acids or bases and the latter being soluble in alcohol. Rest of wheat gluten is polysaccharides, lipids, and minerals. Wheat gluten is more hydrophobic than soy protein. Wheat gluten, as well as hydrolyzed gluten proteins have been studied as adhesives for wood-based panels..$^{53,62,63}$

\subsection{Starch}

Starch is a polysaccharide derived from the seeds, roots and leaves of plants. It acts mainly as the energy storage unit of plants and can be found in large quantities in corn, wheat, potato, rice, tapioca and sago. In pure form, it is insoluble in cold water. Starches can be dry roasted in the presence of an acid catalyst to form dextrins. Depending on roasting time, dextrins can be divided into white dextrins, canary (yellow) dextrins and British gums. Unlike starches, dextrins are soluble in water, and the viscosity of dextrin solution is easier to adjust than that of starches.

Starch consists of glucose units joined by glucosidic bonds. The two fractions of starch are amylose and amylopectin. Amylose is a linear helical chain molecule composed of $\alpha$-(1,4)-bonds and amylopectin is a branched molecule composed of the same $\alpha$ $(1,4)$-linkages except at the branch point, which are $\alpha-(1,6)$-bonds (Fig. 8). Amylopectin and amylose are assembled to form semicrystalline granules. The size and shape of the granule and amylose/amylopectin ratio vary among plant species from which the starch is obtained. ${ }^{64}$ Also, molecular weights of amylose fractions greatly affect the final properties of different starches. Technically, if not economically, it is possible to fractionate linear and helical amylose and branched amylopectin by, for example, 


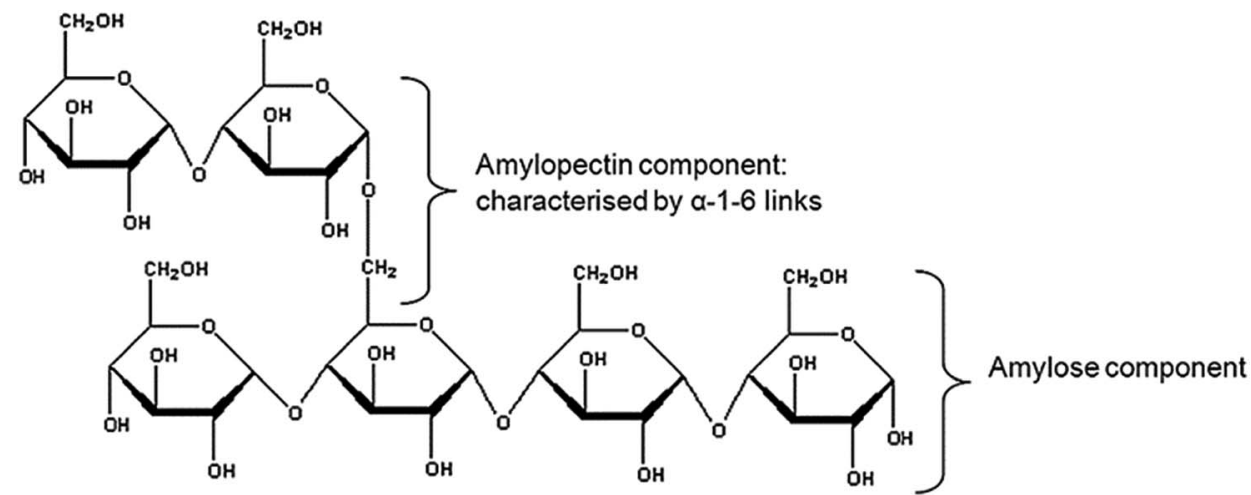

Fig. 8 Starch co-polymer with amylose and amylopectin component (reproduced from ref. 67 with permission from Elsevier Ltd).

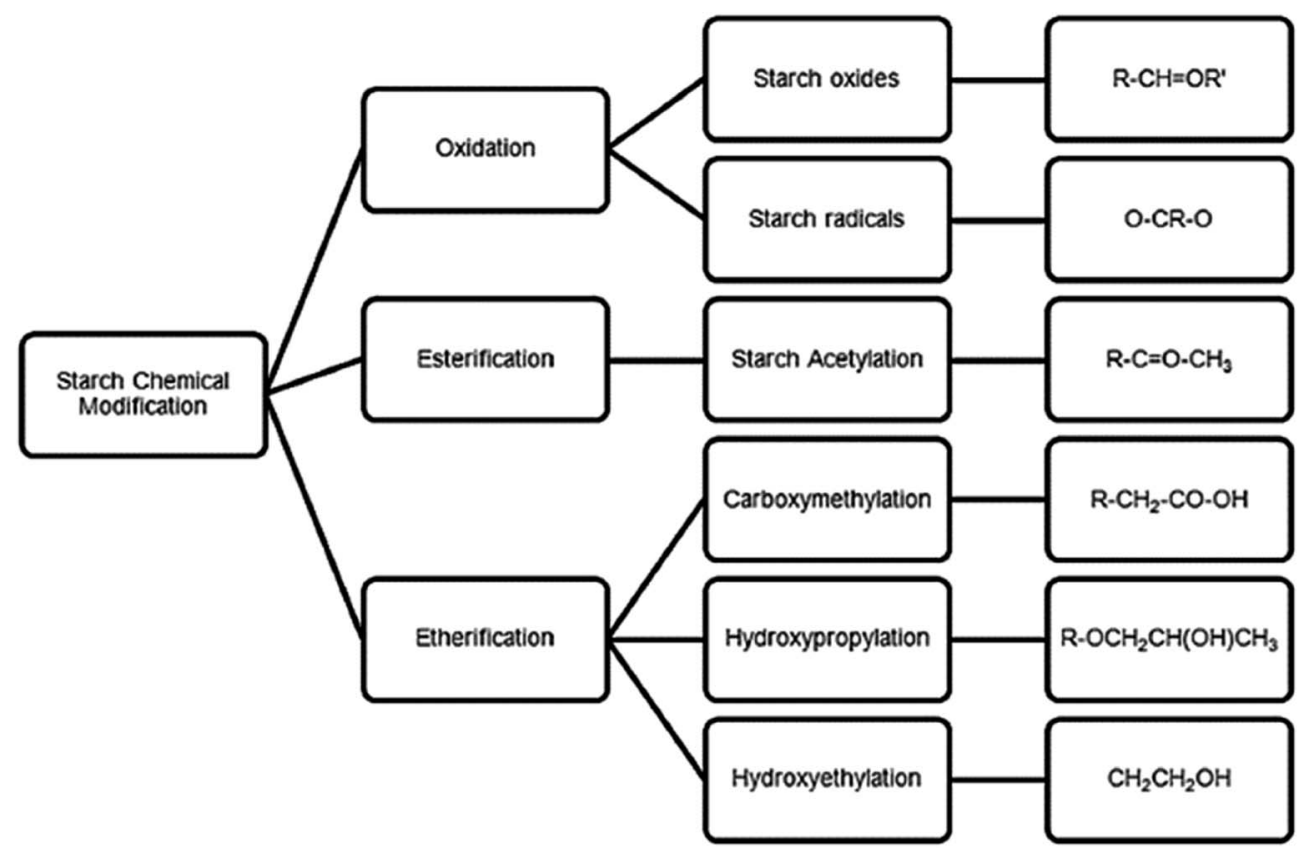

Fig. 9 Schematic summarizing classical chemical methods for starch modification (reproduced from ref. 67 with permission from Elsevier Ltd).

using methanol and butanol solvents according to Schoech's preferential precipitation method. ${ }^{65}$ Methods used for starch analysis include X-ray diffraction (XRD), TGA, and DSC, as for other bio-based materials. Additionally, titration to determine amylose content is important, as the amylose-amylopectin ratio greatly affects properties of starches. ${ }^{66}$

The Stein-Hall process in the 1930s was the first major commercial process for producing starch adhesives for corrugated boxes. A gelatinized starch adhesive, the carrier, is formed in the first cooking phase. In the second phase, the carrier is mixed with starch, water, and borax to form the finished adhesive. ${ }^{68}$ This combination of gelatinized and un-gelatinized starch forms together with a good corrugating adhesive is still important in the packaging industry today. Starch has a large number of glucosidic and hydroxyl groups spread across the polymer chain, which due to their polar nature, have high hydrogen-bonding capability. They are also very hydrophilic, making water resistance of native starch adhesives poor. ${ }^{69}$ Starch also has relatively low bonding strength, making it unsuitable for wood-based panel products in its native form. Thus, starch needs to be highly modified or cross-linked when used in the wood industry. The main types of modifications for starch-based adhesives are chemical, physical, enzymatic and genetic. $^{70}$ The main chemical modifications, oxidation, esterification and etherification, have been reviewed previously ${ }^{67}$ and are presented in Fig. 9. Starch adhesives have very high viscosity due to entanglement of high molecular weight macromolecules. High viscosity makes it very difficult to use them for industrial applications. One way of reducing viscosity is by decreasing the number of entanglements per chain by adding small molecules to swell the polymer network. Another method is by shear refinement. The molecules orient themselves under flow, which decreases the number of entanglements in polymer melts. ${ }^{71}$ 


\section{Development of bio-based adhesives for WBPs}

\subsection{Lignin}

Lignin-based adhesive systems have been the subject of several reviews..$^{15,72,73}$ Self-bonding properties of wood particles and improvement of those by enzyme treatment has been well reviewed in literature. ${ }^{43}$ Kai et al. ${ }^{74}$ in their review paper, discussed potential lignin functionalization for the development of sustainable materials such as biopolymers as reinforcement fillers, antioxidants, UV adsorbents, antimicrobial agents, carbon precursors and biomaterials for tissue engineering and gene therapy. Recently, Zhao et al. ${ }^{75}$ and Wen et al. ${ }^{76}$ have reported the fundamental understanding about lignin solubilization using small-angle neutron scattering (SANS) and nuclear magnetic resonance (NMR) and it will be a very useful tool for analysis of functional lignin for adhesive synthesis.

5.1.1. Partial and total replacement of phenolformaldehyde adhesives. Lignin has been primarily used as partial replacement of phenol in phenol-formaldehyde (PF) resins for plywood production. The chemical structure of lignin lowers the reactivity of the resin, which is a disadvantage in applications where fast curing times are desired. Danielson and Simonson ${ }^{77}$ report that although $50 \%$ of kraft lignin as a replacement for PF resin could give good results regarding resin viscosity, storage stability and bonding ability, the pressing time had to be raised by $30 \%$. Although no difference in plywood bonding is detected between commercially mixed lignin from black liquor and lignin from other wood species (bamboo, eucalyptus), only $15 \%$ phenol can be replaced by lignin without affecting bond properties. ${ }^{78}$

Lignocellulosic ethanol residue (ER), which is the by-product of lignocellulosic ethanol production and rich in active lignin, has also been studied. ${ }^{79}$ Best results are obtained with the replacement of $30 \%$ and $50 \%$ of phenol and the exterior grade plywood produced thereof fulfils the relevant Chinese standard. ER shows a good potential as it has a lower content of polysaccharide, higher content of hydroxyl groups and lower molecular weight than conventional technical lignin. Alkaline, de-alkaline, and sulfonate lignin are liquefied in phenol with $\mathrm{H}_{2} \mathrm{SO}_{4}$ or $\mathrm{HCl}$ catalysts and used to produce resol type PF resins. ${ }^{80}$ The resins can be prepared at lower temperatures and in shorter times and have higher reactivity than normal PF resin. Biorefinery-based technical lignin has also been used in preparing lignin-phenol-formaldehyde synthesis for wood based panel applications. ${ }^{81-83}$ Zhao and Abu-Omar ${ }^{84}$ have performed lignin modifications through deprotection, phenolation and phenol-formaldehyde reactions and have successively improved the uniformity and mechanical and thermal properties of bio-based thermosets.

The presence of guaiacyl-type (G) units in both lignins confirms that both lignins have potential active sites for polymerization (Fig. 10a), similar to phenol-formaldehyde condensation reactions (Fig. 10b): phenol structure has three reactive sites, 2-, 4- and 6-positions, and typical lignin structure has 1 reactive site, 3-position. The second stage of the reaction involves the reaction of methylol groups with other available phenol or methylolphenol, leading first to the formation of linear polymers and then to the formation of hard cure and a highly branched structure.

The similarity between G-type unit of lignin and phenol (Fig. 10a) reveals that lignin can also react with formaldehyde and can be cross-linked with formaldehyde in the same way as in phenol-formaldehyde condensation reaction, as shown in Fig. 10b. Thus, the free 3-position of G-type units in both lignins give significant values compared to the S-type unit, which has both the 3- and 5-position attached to the methoxyl group, preventing the occurrence of a polymerization reaction. a)

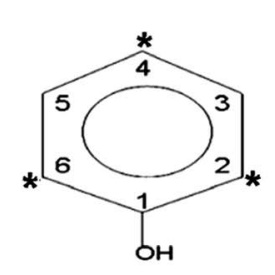

(1)

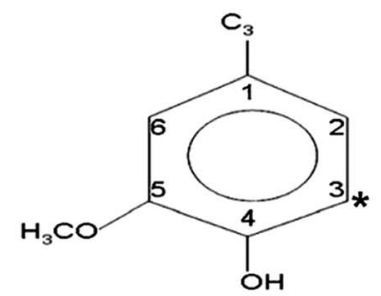

(2) b)<smiles>C/C=C/c1cc(CO)c(O)c(OC)c1</smiles>

Lignin

*= Reactive site

Condensation<smiles>C/C=C/c1cc(Cc2cc(/C=C/C)cc(OC)c2O)c(O)c(OC)c1</smiles>

Fig. 10 (a) (1) Phenol structure with three reactive sites, 2-, 4- and 6-position, and (2) typical lignin structure with 1 reactive site, 3-position. (b) Crosslinking between lignin and formaldehyde (reproduced from ref. 85 with permission from Elsevier Ltd). 

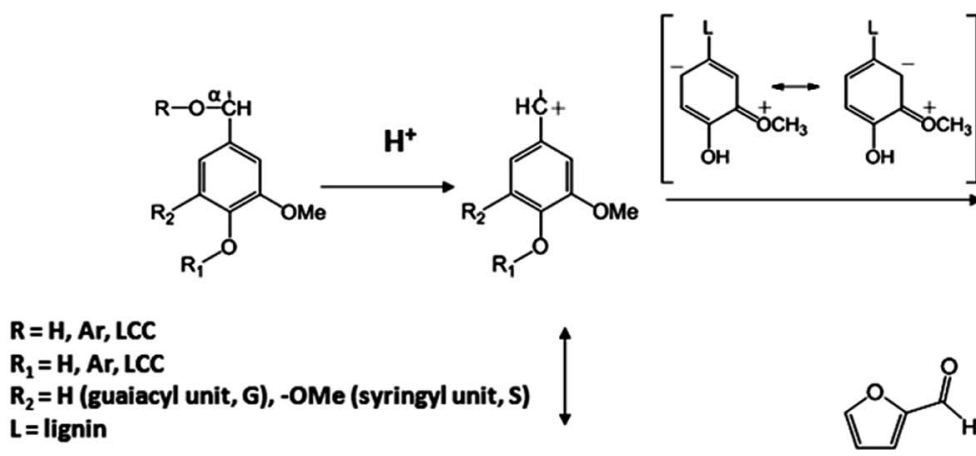
L = lignin
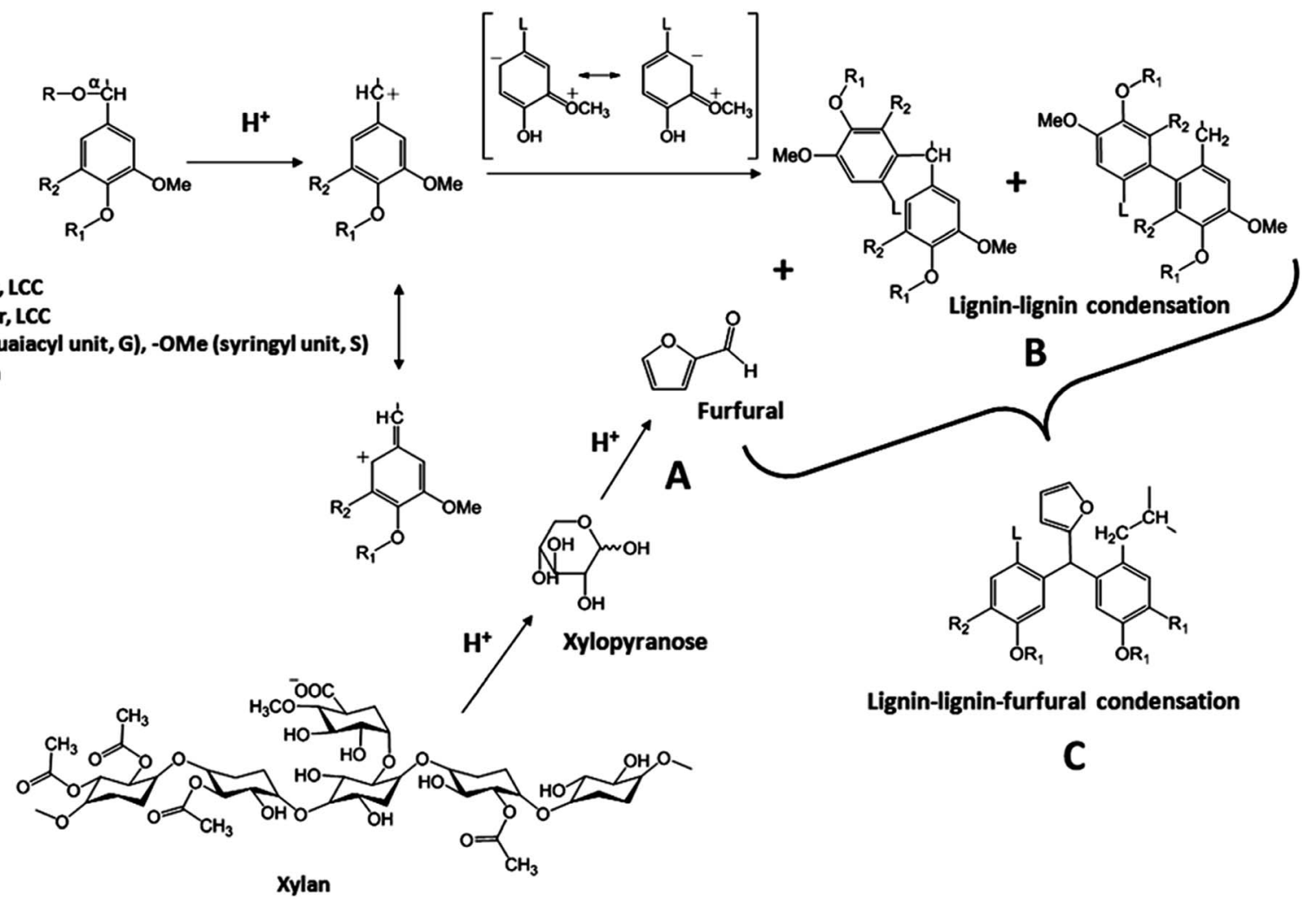

Lignin-lignin-furfural condensation

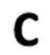

Fig. 11 Proposed mechanism of lignin-furfural condensation products: (A) xylose-based carbohydrates breakdown to furfural; (B) lignin-lignin condensation takes place; and (C) lignin-lignin-furfural condensation product (reproduced from ref. 86 with permission from MDPI AG (Basel, Switzerland)).

5.1.2. Lignin-furfural resin system. In the lignin-furfural resin system, lignin and furfural are proposed to replace phenol and formaldehyde used in PF resins, respectively. ${ }^{86}$ Lignin and furfural are reacted in acidic conditions. The proposed mechanism of lignin-lignin condensation and lignin-furfural condensation is shown in Fig. 11. In high acidic conditions, C2 and C6 carbons of phenylpropanoid units provide high electron density, which make them reactive sites for electrophilic substitution. A carbonium ion at the $\beta$ position is also formed under acidic conditions by proton-induced elimination of water (ether) from the benzylic position. The cleavage of the $\beta$-ether linkage in the $\beta-O-4$ structure results in the carbonium ion reacting further to form Hibbert ketones, analogous to an acidolysis reaction. This may lead to competing reactions of depolymerization and repolymerization of lignin..$^{87,88}$

5.1.3. Lignin modifications. Popular chemical modification methods for lignin are methylolation (hydroxymethylation), phenolation and demethylation. For lignin-phenol-formaldehyde (LPF) resins methylolation and phenolation are industrially the most interesting due to their low costs. The usage of a premethylolated form of lignin in the presence of synthetic PF and pMDI is considered as one of the biggest steps forward in the field of lignin adhesives. ${ }^{89}$ In this case, part of the reaction with formaldehyde is carried out before adding lignin to PF resin. In the main Lederer-Manasse reaction, hydroxymethyl groups are incorporated into lignin aromatic rings to increase reactivity of the molecule. Unwanted side-reactions (Cannizzaro reactions) occur when formaldehyde reacts with itself, thus increasing formaldehyde emissions. Alonso et $a .^{36}$ have studied different lignosulfonate samples and have noted that those from softwood showed better characteristics for methylolation than from hardwood due to the higher number of aromatic protons in their structure. The reactivity of lignin in methylolation also depends on the pulping parameters, $\mathrm{pH}$, temperature, and pressure. ${ }^{90}$ Premethylolated lignin reacts by creating highly effective crosslinks by simultaneous creation of methylene bridges and urethane bridges ${ }^{89}$ and has shown to have higher reactivity than unmodified lignin. ${ }^{91}$

Phenolated organosolv LPF resins are proved to perform better (e.g. improved hardening time) than resins with addition of unmodified lignin..$^{92}$ In this case, the adhesive is formed in two steps. In the first step, the lignin is allowed to react with phenol to increase the number of potential reactive sites. The phenolated lignin is then combined with formaldehyde. Up to $30 \%$ of phenolated organosolv lignin can be used to replace phenol and produce particleboards with mechanical properties comparable to those of particleboards bonded with PF resin. ${ }^{93}$ It is shown that $50 \mathrm{wt} \%$ of phenol can be replaced by phenolated lignin from sources such as eucalyptus bark lignin, ${ }^{94}$ bagasse alkali lignin ${ }^{95}$ and groundnut shells ${ }^{96}$ and still improve adhesion strength on teak wood specimens compared with PF resins. According to these findings, the phenolation step before polymerizing LPF resin is critical in order to successfully increase lignin portion of the final resin. In that respect, lignin concentration, 
formaldehyde-to-phenol molar ratio, catalyst concentration, reaction time and reaction temperature are optimized. ${ }^{94}$

As methyl groups of methoxyl groups block potentially reactive aromatic hydroxyl groups, reactivity of lignin and its ability to form crosslinks can be improved by demethylating lignin aromatic rings. Demethylation can be done chemically or enzymatically (e.g. laccase, peroxidase). ${ }^{97}$ Laccase reacts on phenolics via non-specific oxidation reactions. Oxidative degradation is also an established method of depolymerization of lignin present in residues from pulp mills. However, an oxidation step leads to additional cost and a significant increase in lignin reactivity cannot always be guaranteed. ${ }^{98}$ Various fungi can be potentially used to modify lignin. Brown-rot fungi can demethylate lignin and partially oxidize side-chains.

5.1.4. Lignin with different crosslinking agents. Some authors have reported a total replacement of PF resin in particleboard manufacturing by using lignin in combination with glyoxal and pMDI or tannin. ${ }^{99,100}$ Lignin contains both aliphatic and phenolic hydroxyl groups, which can react with isocyanates of MDI to form urethane groups. ${ }^{101}$ El Mansouri et al. $(2007)^{99}$ have used lignosulphonate in combination with glyoxal and pMDI. Particleboards of good internal bond strength can be produced with glyoxalated lignin (lignosulphonate) and pMDI ratios of 60/40. Glyoxal is a non-toxic aldehyde but less reactive than formaldehyde. ${ }^{99}$ Navarrete et al. $(2012)^{102}$ have used glyoxalated lignin from kraft and organosolv processes (from wheat straw) and mimosa tannin. Tannin is often a more reactive substitution for phenol but it is also less available and more expensive. A higher internal bond strength is obtained for boards glued with a 40/60 lignin/tannin adhesive. Combinations of glyoxalated wood and wheat-straw lignin with MDI and mimosa tannin adhesives are also reported and the results are highly dependent on MDI amount. When combined with MDI, low molecular weight lignin performs better than high molecular weight lignin. ${ }^{\mathbf{1 0 3}}$ Adhesives for particleboards and plywood with 94\% content of natural origin are produced from wheat-straw derived organosolv lignin, glyoxal, tannin and hexamine. A minimum of $45 \%$ tannin is required for an acceptable internal bond strength of boards. ${ }^{104}$ Finally, a total replacement of PF resin with lignin and glutaraldehyde has been attempted; glutaraldehyde is a dialdehyde that can be obtained from natural sources. The resins produced from industrial organosolv lignin (from sugarcane bagasse) and soda/AQ lignin (from Miscanthus fibers) with glutaraldehyde are analysed with SEC and ${ }^{31} \mathrm{P}-\mathrm{NMR}$ and their composites are produced. The composites containing these resins and sugarcane bagasse fibers show better impact and flexural strength when compared to composites with pure PF resin. ${ }^{38}$ Table 4 shows the latest literature about lignin-based adhesives and their application in WBPs.

Another very interesting aspect has also emerged in the area of lignin self-crosslinking. ${ }^{\mathbf{1 0 5 , 1 0 6}}$ The in situ treatment of wood fibers with laccase shows distinct increases in molecular weight of lignin directly due to formation of lignin covalent interbonding, as shown in Fig. 12. ${ }^{106}$ Fabrication of MDF using this process has been reported in various articles, ${ }^{106-108}$ and this area is continuously developing towards industrial-scale production.
Recently, for the first time, Prof. Sun's research group reported the self-crosslinking of industrial alkali lignins for green wood-lignin composite fabrication via heat-treatment. ${ }^{109}$ They reported the decrease of $\beta-O-4^{\prime}$ linkages content, accompanied by the formation of $\beta-\beta^{\prime}, \beta-5^{\prime}$, and $\beta-1^{\prime}$ linkages under mild heat treatment temperatures $\left(130-170{ }^{\circ} \mathrm{C}\right)$, and most of the $\beta-O-4^{\prime}$, $\beta-\beta^{\prime}, \beta-5^{\prime}$, and $\beta-1^{\prime}$ linkages nearly disappeared at a higher temperature $\left(180{ }^{\circ} \mathrm{C}\right)$. A self-crosslinking mechanism was proposed as shown in Fig. 13.

\subsection{Tannin}

5.2.1. Commercial and most common tannin adhesives. Commercial tannin-formaldehyde applications already exist and several reviews on the use of tannin as a wood adhesive can be found in literature. ${ }^{\mathbf{8 9 , 1 1 0}}$ Currently, tannins are not available in large enough quantities to compete with synthetic adhesives in most parts of the world. Only South Africa and South America have enough availability for local tannin production (e.g. from quebracho) needed for utilization as adhesives. It should be noted that tannin-based adhesives typically give particleboards with better water and moisture tolerance compared to those given by UF resins. Although most commercial applications and studies focus on condensed tannins due to their higher reactivity, some studies have been done on the use of hydrolysable tannins as wood adhesives. They react through their low reactivity meta-sites, but it is still possible to substitute a large amount of phenol in PF resins by hydrolysable tannins. ${ }^{111}$

It has been mentioned already that tannin has been used together with lignin for different types of wood adhesives. If no formaldehyde is used, lignin can be glyoxalated before mixing with tannin and a hardener (e.g. hexamine). The formaldehyde emissions of particleboards glued with the studied mimosa tannin and glyoxalated wheat straw lignin according to EN 7173 is $0.92-1.12 \mathrm{mg} \mathrm{kg}^{-1} \cdot{ }^{100}$ Also, other bio-based materials are suitable to be used with tannins to form adhesives. For example, corn starch-mimosa tannin with hexamine as the hardener has been used as an adhesive for plywood. One improvement and research area on starch-tannin adhesives is the reduction of high viscosity that limits their industrial possibilities. ${ }^{\mathbf{1 1 2}}$

Tannin adhesives due to their phenolic nature have very low formaldehyde emissions. The emissions have been even further reduced by using non-emitting hardeners or by using tannins that are cured by auto-condensation in the absence of aldehydes. ${ }^{89}$ The autocatalytic hardening can occur in highly reactive tannins, such as in procyanidins, without the need of an external catalyst. For slower-reacting tannins, such as prorobinetinidins, autocondensation occurs when a small amount of alkaline $\mathrm{SiO}_{2}$ is present at high $\mathrm{pH} .{ }^{113}$

In auto-condensation, the O1-C2 link of the flavonoid repeating unit is opened, which then drives auto-condensation between the reactive $\mathrm{C} 2$ of the open chain and free sites in $\mathrm{C} 6$ or C8 of the flavonoid unit in another polymer chain. Autocondensation can also occur at room temperature at higher $\mathrm{pH}$, increasing the viscosity of the tannin adhesive. Different tannins have different auto-condensation behaviors and require different $\mathrm{pH}$, e.g. for mimosa tannins, auto-condensation 


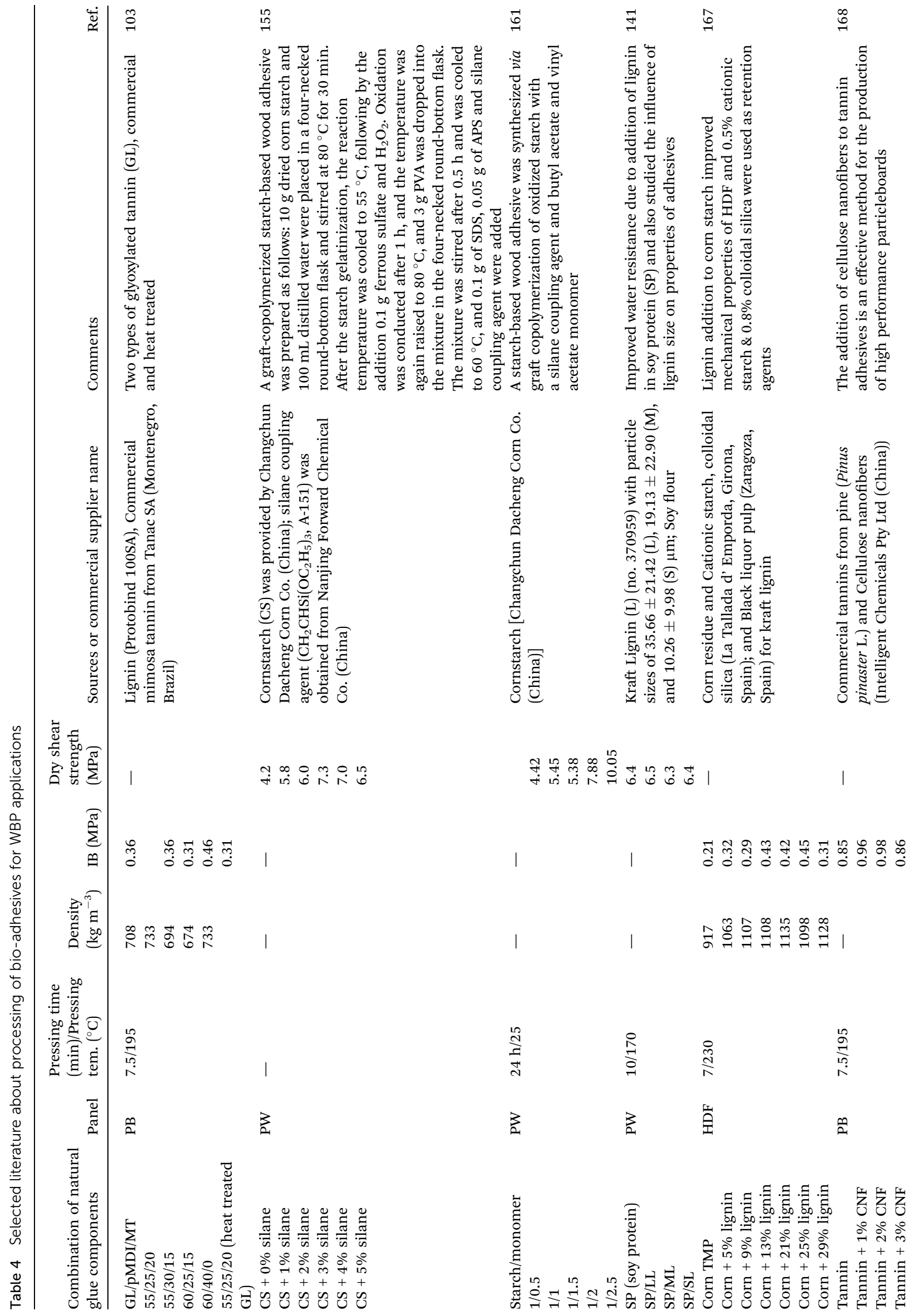




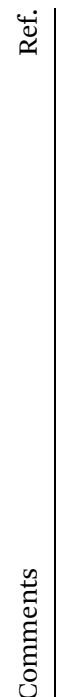

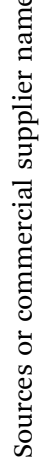

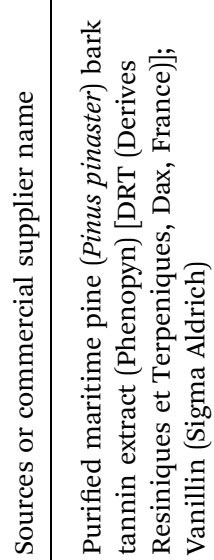

$\stackrel{ }{ }$

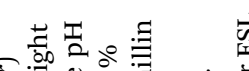

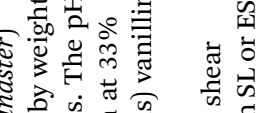

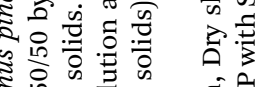

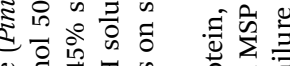

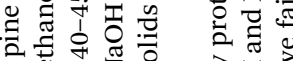

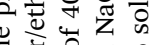

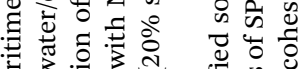

药.

चु

要

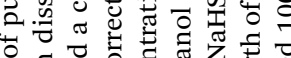

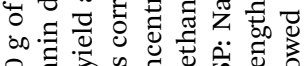

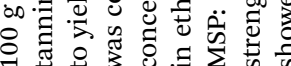

政的

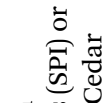

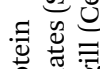

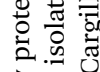

家 :

苨

家宫.

表安

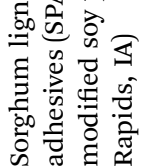

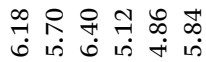

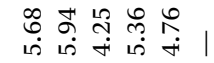

虽

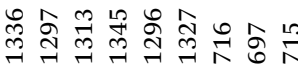

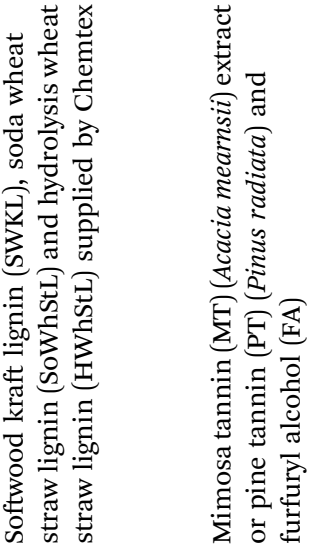

苋政

居洁起

苋

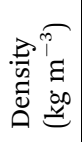

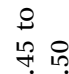

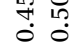

:

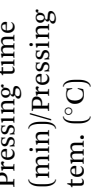

ล

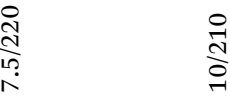

高

일

:

狊

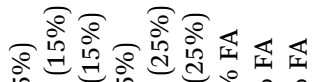

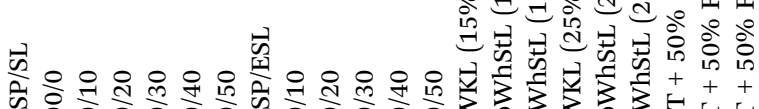

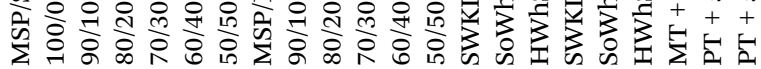

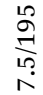

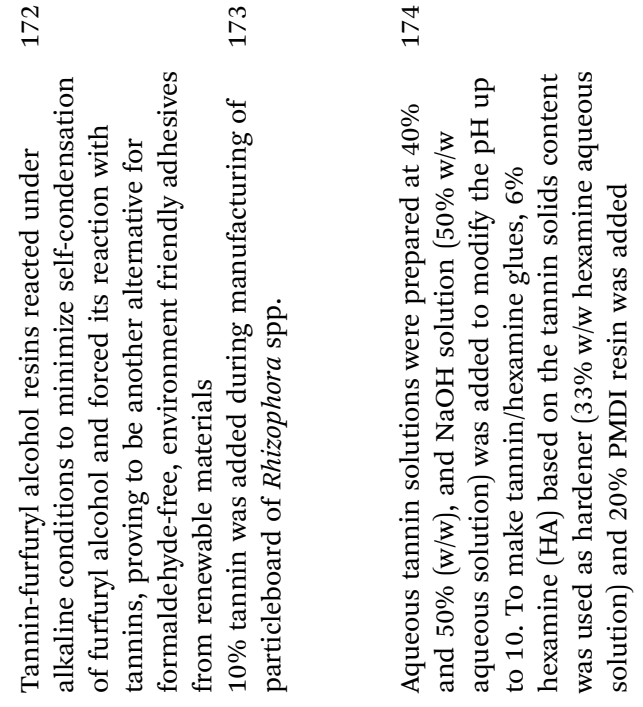

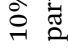

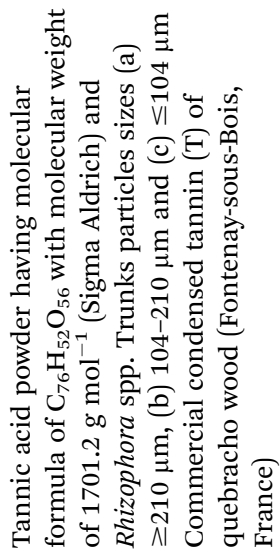

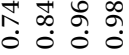

तु่

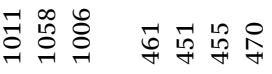

离

늠

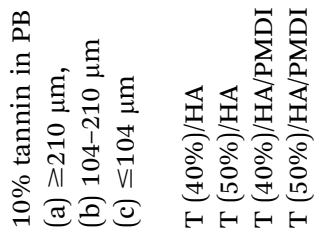




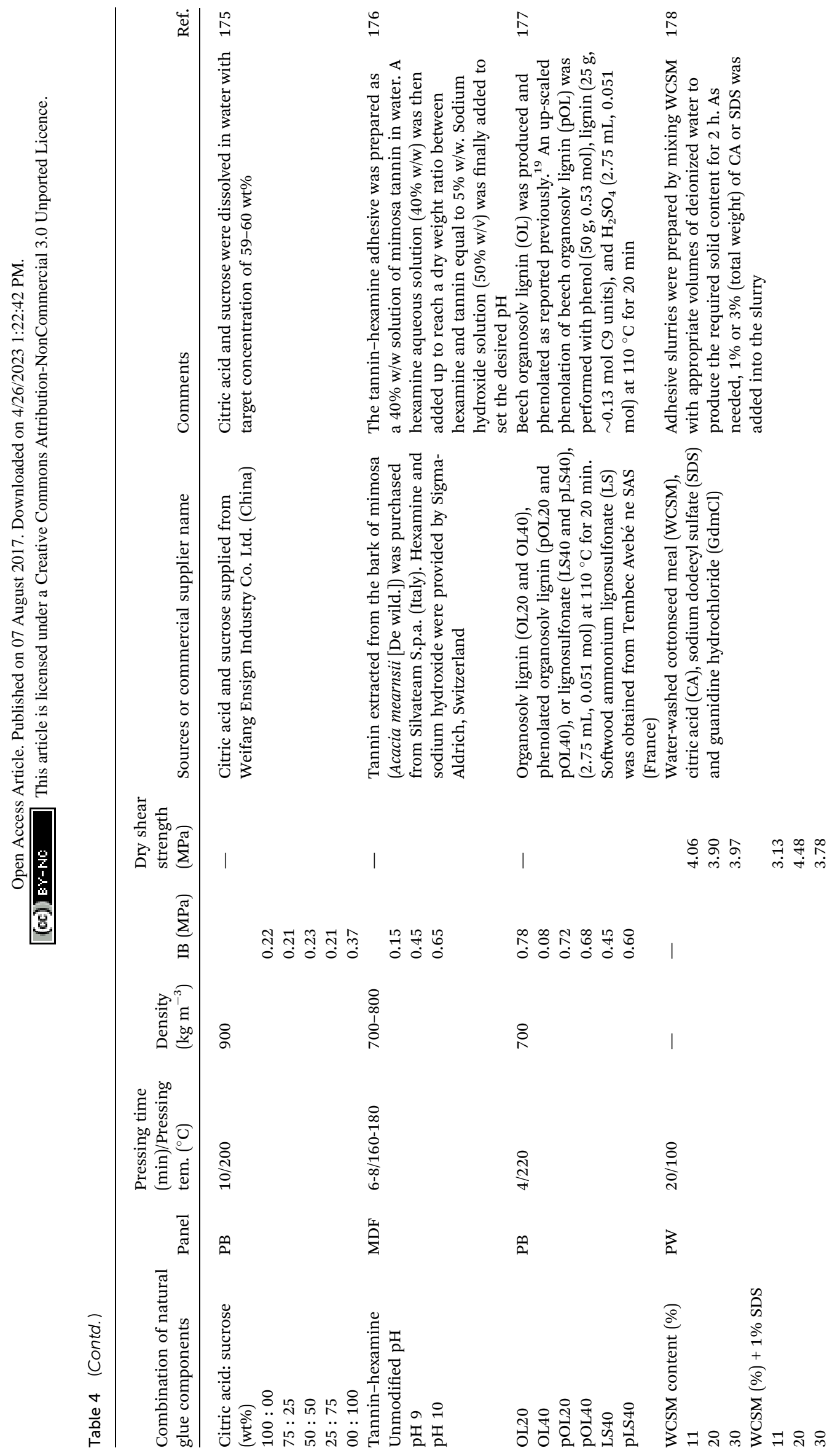




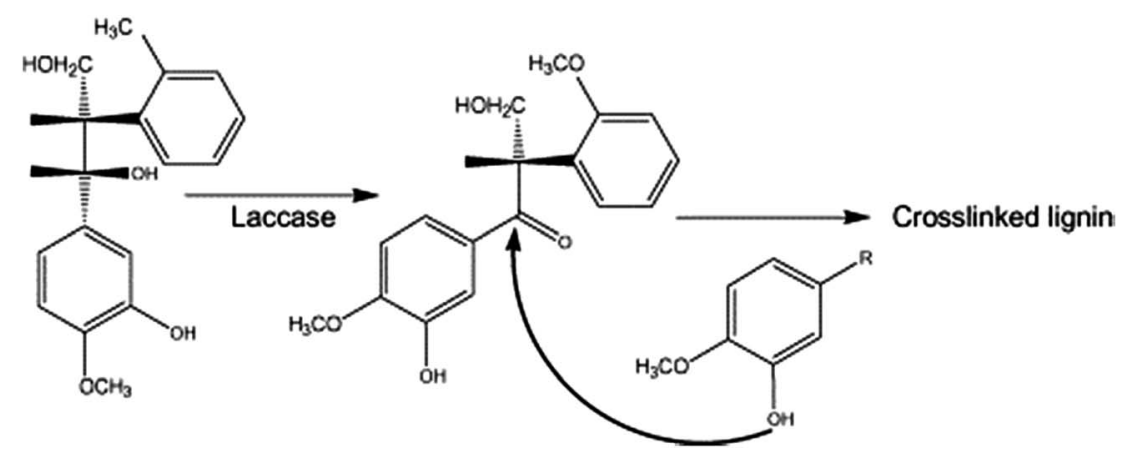

Fig. 12 Laccase-mediated oxidation of lignin model compound and putative further reaction leading to lignin crosslinking (reproduced from ref. 105 with permission from Elsevier Ltd).

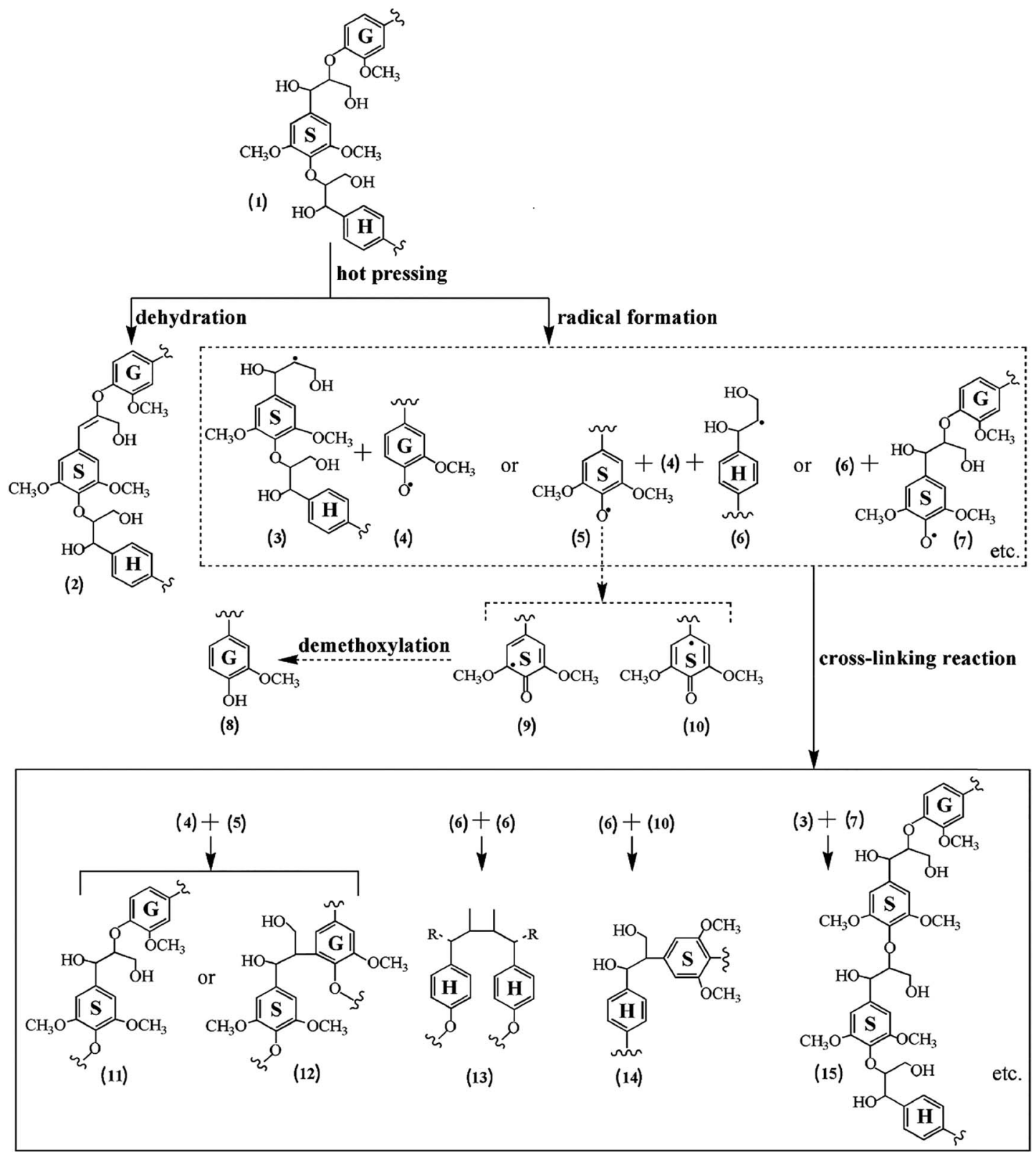

Fig. 13 Proposed self-bonding mechanism of lignin (reproduced from ref. 109 with permission from American Chemical Society). 
occurs at alkaline $\mathrm{pH}$ (ref. 114) and for Acacia Nilotica spp. Tannins, at their initial acidic pH. ${ }^{115}$

Increasing tannin content in PF-tannin adhesives reduces formaldehyde emissions proportionally. However, high concentrations of tannin in PF resins lead to higher viscosity and shorter pot lives, because tannins are more reactive than phenol towards formaldehyde due to resorcinol and/or phloroglucinol rings in their structure. ${ }^{113}$ Jahanshaei et al. ${ }^{116}$ replace up to $30 \%$ of phenol in PF with condensed Quercus castaneifolia bark tannin. Replacement above 30\% deteriorates mechanical properties and increases water absorption and swelling thickness of particleboards. Valonea tannin (VT)-modified phenolformaldehyde resin has been prepared by Li et al. ${ }^{117}$ via copolycondensation mechanism; FTIR and ${ }^{13} \mathrm{C}$ NMR analytical results confirm that VT is composed primarily of galloyl groups, hexahydroxydiphenol groups and glucose. Table 4 shows some latest literature about tannin-based adhesives and their application in WBPs.

5.2.2. Alternative crosslinking agents. To produce low- and non-emitting tannin wood adhesives, different crosslinking agents have been used and compared with formaldehyde. Even though formaldehyde provides faster curing than the alternative crosslinking agents, the pot life is extremely short. Thus, formaldehyde has been discarded as a crosslinker at least for the more reactive tannins, such as chestnut tannins. According to study by Vázquez et al. ${ }^{118}$ glyoxal has the second shortest pot life, followed by hexamine and tris(hydroxylmethyl)nitromethane. Basso et al. ${ }^{119}$ have reported for the first time a reaction of catechin and polyflavonoid tannins with TEP, leading to polymerization and cross-linking. The FTIR, MALDI-ToF, ${ }^{31} \mathrm{P}-$ NMR and ${ }^{13} \mathrm{C}-\mathrm{NMR}$ analyses reveal that the reaction takes place mainly on the $\mathrm{C} 3$ of the flavonoid heterocycle ring and on the aromatic $\mathrm{C} 4^{\prime}$ and $\mathrm{C}^{\prime}$ carbons of the flavonoid B-ring.

Hexamethylenetetramine (hexamine) has been used as a cross linking agent (hardener) for tannin adhesives since the 1950s, when it could only be used for interior particleboards due to moisture sensitivity. Unlike formaldehyde, hexamine cannot react with tannin unless intimately mixed with it or unless it decomposes to formaldehyde and ammonia, in which case the panel properties are further lowered. It has been proven that with very reactive nucleophilic sites, such as those of highly reactive phenols (tannin), amines, amides or anions, hexamine is not a formaldehyde-yielding compound. This is because slow hexamine decomposition forms reactive imines that react very fast with nucleophiles and do not allow hexamine to reach its final decomposition products of ammonia and formaldehyde. ${ }^{120}$ Hexamine was used as a hardener for tannin adhesives used in industrial panels produced in Chile during 1993-2002. The good potential of tannin adhesives for industrial use have been reported by Valenzuela et al. (2012). ${ }^{121}$

Methylolated nitroparaffins, such as the simplest and least expensive tris(hydroxymethyl)nitromethane (TRIS), function well as crosslinking agents for tannin adhesives. It has been shown to lower formaldehyde emissions and increase pot life when used as a proportional substitution of other hardeners for tannin adhesives. ${ }^{122}$ However, it also requires much higher curing temperatures than other hardeners. ${ }^{118}$ Other curing agents, such as fatty amides based on vegetable oils, have also been tested as crosslinkers for tannin adhesives. Patel et al. ${ }^{123}$ have tested $N, N$-bis(2-hydroxyethyl) fatty amide (HEFA) from Karanja oil and rice bran oil as cross-linkers for tannin. $\mathrm{H}_{2} \mathrm{SO}_{4}$, $\mathrm{NaOH}$, and $\mathrm{NH}_{4} \mathrm{Cl}$ are used as curing catalysts. $\mathrm{NaOH}$ gives slightly lower joint strength for both rice bran oil and Karanja oil. The increase in HEFA content increases chemical resistance, tensile strength and impact strength of the bonded joints. HEFA from Karanja oil gives slightly better results, because the reactivity of methylol groups in it is higher than in rice bran oil. Recently, it has been reported that a suitable mixture of tannin and EPL (30\% tannin and 13\% EPL) gives an adhesive that passes the EN 314 class 1 standard, with respect to both water resistance and adhesive strength. ${ }^{124} \mathrm{~A}$ chemical route for possible crosslinking of tannin and protein has also been proposed, as shown in Fig. 14.

\subsection{Soy protein}

A detailed review on the use of soy protein as wood adhesive can be found in literature. ${ }^{16,56,57,125}$ The use of soy protein as an adhesive dates back to the ancient times but its commercial use in plywood production began only in the 1930s. ${ }^{126}$ Back then, soy protein adhesives were used for wood and paper and as binders in coatings and paints. The soy proteins used as plywood adhesives were typically denaturized by caustic treatment. The products had typically short pot lives, poor biological stability, low solid content, slow pressing times and very poor water resistance, which limited them to mainly interior applications. ${ }^{127}$ In the 1960 s, most soy-based adhesives were replaced with synthetic adhesives, such as phenol-formaldehyde (PF) and urea-formaldehyde (UF) adhesives.

The new developed soy adhesives have higher moisture tolerances and are stronger than those known before the 1960s.
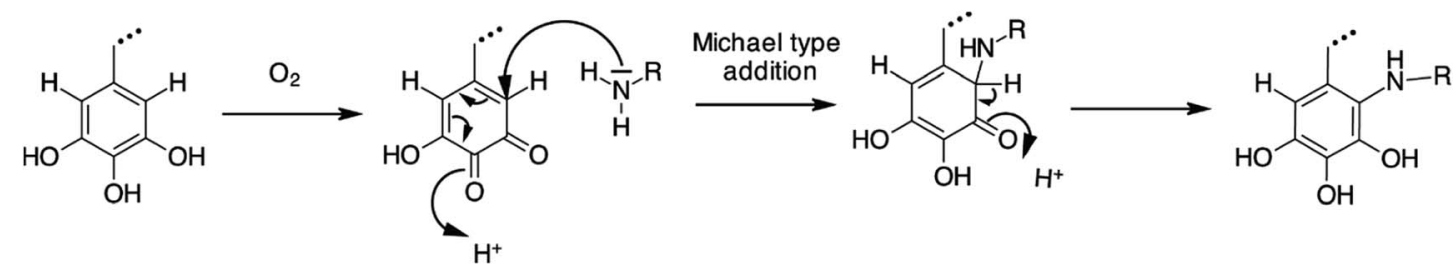

Fig. 14 Plausible reaction mechanism for tannin-based adhesives. Terminal gallic acid (top left) is oxidized to a diketone (top right). The diketone then reacts with the amine group of the protein, which results in tannin and protein becoming cross-linked (reproduced from ref. 124 with permission from Elsevier Ltd). 
As a wood adhesive, soy protein is inexpensive, easy to handle, has low pressing temperatures and can bond wood with relatively high moisture content. However, soy protein adhesives have high viscosities and short pot lives and the wood composites bound with them have relatively low strength, low water tolerance, and are sensitive to biological degradation. ${ }^{\mathbf{1 4}}$ Protein adhesives are also quite sensitive to changes in temperature, $\mathrm{pH}$, ionic strength and pressing conditions. The adhesive properties highly depend on protein content. ${ }^{128}$ The high viscosity of soy adhesives can be lowered by using low solids' content or by hydrolysis of the protein. Hydrolysis breaks the protein macromolecules into small fragments, which also leads to inferior bond strengths. Hydrolysis can be done using hot caustic or enzymatic treatment reactions. ${ }^{129}$ Another less evaluated aspect of using soy adhesives is in particleboards produced from straw instead of wood. Soy protein adhesives have been proposed to be more suitable than formaldehyde based adhesives for most straw boards since the straw surface is hydrophobic due to silica and wax components. ${ }^{\mathbf{1 3 0}}$

5.3.1. Denaturation and modification of protein adhesives. To use a protein as an adhesive, denaturation is necessary to expose more polar groups for solubility and bonding via hydrogen bonds. ${ }^{\mathbf{1 2 8}}$ Denaturation is a term for a modification that changes the secondary, tertiary or quaternary structure of the protein molecule without breaking covalent bonds. This process uncoils the protein and exposes hydrophilic groups for modification reactions. Proteins can be denatured by exposure to heat, acid/alkali, organic solvents, detergents or urea. Research on soy protein isolates has shown that both detergent concentration and the $\mathrm{pH}$ value have significant effects on adhesive strength of modified soy protein isolate. ${ }^{\mathbf{1 3 1}}$

It is possible to unfold protein complexes with urea, as its oxygen and hydrogen atoms interact with hydroxyl groups of the proteins and break down the hydrogen bonds in the protein body. ${ }^{132}$ Urea at a very high concentration also breaks the secondary structure of the protein, but this can have a negative effect on adhesive properties of the protein. Soy proteins can also be treated with sodium dodecyl sulfonate (SDS), sodium dodecyl benzene sulfonate (SDBS) and enzymes to break apart the quaternary protein structure while still retaining some part of the secondary structure. ${ }^{133}$ Guanidine hydrochloride (GuHCl) can also denature protein. In a fiberboard study by Zhong et al. ${ }^{\mathbf{1 3 4}}$ the best $\mathrm{GuHCl}$ concentration for denaturing soy protein isolates (SPIs) is $1 \mathrm{M}$. Increasing pressing temperature is the major physical method to cause denaturation of protein molecules, and temperatures above $75{ }^{\circ} \mathrm{C}$ can cause further denaturation of SPI. ${ }^{\mathbf{1 3 4}}$

Sodium hydroxide has been shown to denature higher molecular weight soy protein better than sodium carbonate. After denaturation, it is important to stabilize the protein by adding, for example, formaldehyde and phenol. Some crosslinking in the protein occurs after the addition of formaldehyde. The reaction between soy flour and formaldehyde and the possibilities to replace PF resins has been studied by Lorenz et $a{ }^{\mathbf{1 3 5}}$ using gel permeation chromatography. The chemical modification of soy proteins is shown to increase its adhesion properties, but such methods often require the use of more expensive SPIs. Maleic anhydride (MA) is one way to modify soy protein. It reacts more readily with amino groups than with hydroxyl groups in the soy protein. However, this modification alone does not increase dry shear strength or water tolerance enough. Combining MA-grafted SPIs with polyethyleneimine (PEI) has been noted to improve adhesive performance. The highest shear strengths in the tested plywood samples are achieved with $20 \%$ PEI content. ${ }^{\mathbf{1 3 6}}$ The particleboard pressing conditions for soy flour-PEI-MA-NaOH adhesives are optimized by $\mathrm{Gu}$ and $\mathrm{Li}^{137}$ The largest increase in MOR, MOE and IB is detected when the temperature is increased from $160{ }^{\circ} \mathrm{C}$ to $170{ }^{\circ} \mathrm{C}$. Above this temperature, only minor changes are detected in MOR. Thus, for SF-PEI-MA-NaOH adhesive, the pressing temperature of $170{ }^{\circ} \mathrm{C}$ and pressing time of $270 \mathrm{~s}$ for a $17 \mathrm{~mm}$ three-layer board is found to be the most desirable. Poly(glycidyl methacrylate) (GMA) contain both methacrylic and epoxy groups that react readily with many different functional groups. Grafting GMA into canola protein has been shown to be possible and is known to increase adhesive strength and water tolerance of the adhesive when tested on veneer sheets. ${ }^{58}$ Table 4 shows some latest literature about soy protein based adhesives and their application in WBPs.

Soy protein has also been tested in polyketone-based veneer adhesives. High molecular weight polyketones show many interesting properties such as biodegradability; photodegradability; chemical resistance to acids, bases and solvents; and stability against electrolytic corrosion. Replacing some of the polyketones with soy protein does not affect the performance of the wood adhesive and it is also economical due to the lower price of soy protein. ${ }^{\mathbf{1 3 8}}$

Proteins from different sources react differently to modifications and additives. For example, in a study by Cheng et al., ${ }^{139}$ cotton seed protein adhesive has been found to benefit from modifiers with anionic charge in them (e.g. glutamic acid, acetic acid, butyric acid), while no positive change is detected in soy proteins adhesive formulations. Similarly, it has been found that adhesive properties and water resistance of soy protein isolates is significantly better than that of wheat gluten protein after alkali modification. ${ }^{\mathbf{1 4 0}}$ Lignin-modified soy protein adhesives with improved mechanical and water resistance properties have been reported by Pradyawong et al. ${ }^{\mathbf{1 4 1}}$ The water resistance of soy adhesives is also improved by the addition of soy-oil based waterborne polyurethane. ${ }^{\mathbf{1 4 2}}$

5.3.2. Soy protein with formaldehyde and synthetic resins. The cross-linking reaction of soy protein with formaldehyde is often easily reversed unless an excess amount of formaldehyde is used. The non-co-polymerized soy adhesive remains water soluble after curing and it is sensitive to moisture. Researchers have been using various methods to increase the water tolerance of high-soy-protein-content adhesives, basically by proper denaturation, stabilization and crosslinking reactions. Wescott et $a .^{127}$ have focused on overcoming this problem by denaturizing, modifying and co-polymerizing soy flour. After denaturation, the functional groups are stabilized through reaction with formaldehyde. Formaldehyde prepares the soy flour for copolymerization and it reduces biological degradation of the final product. However, this reaction of formaldehyde with 
some amino acids yields cyclic structures, preventing amino acid from being incorporated into the polymer backbone. ${ }^{110}$

Historically, replacement of synthetic resins partially with soy protein has shown to decrease reactivity of resin and increase viscosity compared to synthetic adhesives. Adding soy protein as a modifier to UF resin is not found to reduce formaldehyde emissions. ${ }^{143}$ When compared to $100 \%$ soy adhesives, the properties are however improved when combining cheap soy flour with a synthetic adhesive such as MUF and UF. In soyMUF adhesives, methylene bridges are formed between soy and MUF molecules. It is found that the addition of MUF increases water tolerance and wet shear strength of soy adhesives, but MUF content has to be above $20 \%$ for the adhesive to pass the three-cycle water-tolerance test. ${ }^{144}$

Using soy proteins to partially replace PF adhesives is problematic, since the amine groups of soy proteins do not react well under basic conditions of PF formulations. ${ }^{110}$ Wescott et al. ${ }^{127}$ have used soy-PF resin containing $40 \%$ soy in the production of strandboards showing good water tolerance properties, even withstanding $2 \mathrm{~h}$ of boil tests. Based on water extraction and elemental analysis results, $55-86 \%$ of previously water-soluble soy flour is converted to water-insoluble material through copolymerization with resole PF resin.

5.3.3. Different crosslinking agents. The most commonly used crosslinking agents for soy protein adhesives are polyamides. However, since polyamides often have low solid content and high viscosity, alternative curing agents have also been studied in the literature. Interior plywood panels have been made from soy flour using a new curing agent obtained from reaction of epichlorohydrin and ammonium hydroxide in water. The water resistance is improved by addition of $\mathrm{NaOH}$ to the adhesive formulation. ${ }^{145}$ Polyamidoamine-epichlorohydrin (PAE) resin, commercially known as Kymene $557 \mathrm{H}$, has been tested as a crosslinker for soy proteins. PAE has a functional group of hydroxyl-azetidium (cationic four-membered ring structure) that can react with carboxylic acid groups and with amino groups in PAE and in soy protein, forming a threedimensional water-insoluble network. An SPI-Kymene adhesive studied by Li et al. ${ }^{14}$ gives light-coloured glue lines and shows good potential. The high price of SPIs, however, makes these adhesives cost-ineffective and soy flour is a more economical solution. Soy protein adhesives have also been used in the "honeymoon" process, in which hydrolyzed soy protein and phenol-resorcinol-formaldehyde (PRF) are applied to each end of two finger-jointed boards. This process requires that the two components be kept separately as premixing would lead to extremely short pot life. ${ }^{135}$ Hydrolyzed gluten proteins have been tested for manufacturing particleboard adhesives. Combining them with pMDI or tannin using hexamine hardener produces adhesives with high natural content and no aldehyde emissions. The pMDI content in pMDI/gluten adhesives have to be over $30 \%$ if viable pressing times are desired. Glutenformaldehyde resin, alkali-treated gluten, and gluten-glyoxal resin have been tested. ${ }^{62}$ Yuan et al. ${ }^{146}$ have recently prepared a cross-linked soy adhesive; they use a 2 -step process consisting cross-linking soybean soluble polysaccharide in soybean meal and then conjugating soy protein.
Soy protein is modified by alkaline calcium, the active hydrophilic groups chelated with calcium or ions to form insoluble calcite or aragonite crystals. During the adhesion process with wood substrate at high $\mathrm{pH}$, the modified soy protein formed ionic bonding. ${ }^{147}$ A schematic model for the adhesive phenomenon (Fig. 15) has been proposed, and it is adopted from naturally occurring biomimetic hybrid adhesives in gecko and mussel adhesion.

\subsection{Starch}

The adhesive bonding strength of natural starch is not strong enough to glue wood, and the amount of research done is not as great as for some of the other bio-based adhesives. Most recent starch adhesive research focuses on replacement or extender for solid wood dispersion adhesives to reduce material cost and increase viscosity. ${ }^{\mathbf{1 8 , 1 4 9}}$ The studies on the use of starch as a wood adhesive have focused on corn starch in starch/polyvinyl alcohol ${ }^{150}$ starch/isocyanates ${ }^{151}$ and starch/tannin ${ }^{71}$ adhesives. Also, rice, rye, wheat and potato starch have been evaluated for use in particleboards. The adhesive properties of starch vary greatly depending on where it is derived from. ${ }^{64,66}$

Starch adhesives rely on hydrogen bonding forces, which are much weaker than chemical bonds. They also easily form hydrogen bonds with water molecules, leading to poor water resistance. Higher bonding strength and better water resistance can be achieved by crosslinking starch using crosslinking agents such as sodium borate, epoxy chloropropane, hexamethoxymethylmelamine, formaldehyde, and isocyanates. ${ }^{151}$

Starch is not soluble in water and it is easily precipitated due to the high amount of intra- and intermolecular hydrogen bonding. Thus, starch adhesives tend to crystallize upon drying, resulting in reduced contact area and loss of adhesion when used for veneer gluing in plywood manufacturing. Crystalline particle formation of starch chains can be disrupted by heating in water. First, in this gelatinization, the heating breaks hydrogen bonds in the starch helices, allowing water to penetrate into the structure. Starch paste is formed when the heating is continued with excess water. The paste consists of dissolved amylose and starch granule fragments (D'Amico et al., 2010). Other modifications to open tightly bound starch granules are acid treatment, alkali treatment, derivatization, oxidation and enzyme treatment. ${ }^{152}$ Chemical, physical, enzymatic and genetic modifications of starch for different applications have been thoroughly reviewed by Kaur et al. ${ }^{70}$ Wang et al. ${ }^{153}$ have studied the influence of starch hydrolysis on various characteristics of starch-based wood adhesives. Up to two hours of acid hydrolysis improves grafting reaction and reduces steric hindrance of adhesives. Two hours of acid hydrolysis of starch can inhibit retrogradation of starch molecules by preventing starch chains from re-arranging and locking water molecules in the adhesive system.

5.4.1. Crosslinking and other modifications of starch. Crosslinking of starch is possible with isocyanates (such as pMDI) to improve wet and dry bonding strength of plywood. ${ }^{154}$ Isocyanates readily react with various functional groups, such as hydroxyl, amino and carboxyl groups. They have good bonding 


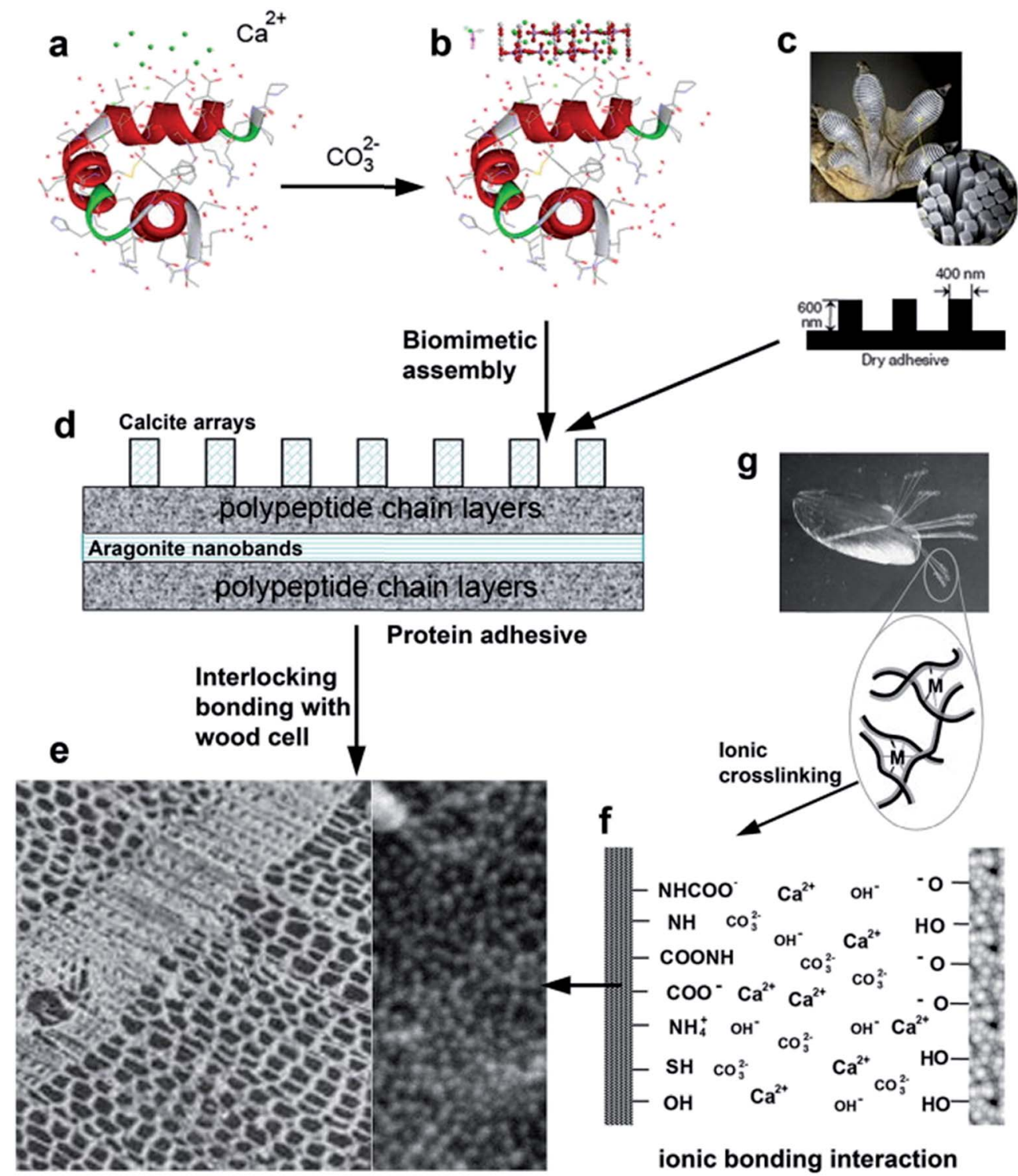

Fig. 15 Schematic describing the inspiration of gecko and mussel adhesives (c and g, respectively), route of synthesis for soy protein hybrid adhesives ( $a, b$, and d), and an illustration of adhesion interface structure and mechanical interlocking and ionic crosslinking interaction (e and $f$, respectively) (reproduced from ref. 147 with permission from Elsevier Ltd).

properties, water and aging resistance, no formaldehyde emissions, and are adaptable to various applications. However, isocyanates are very expensive and need to be used in stabilized form due to their high reactivity towards moisture. Extra precaution in the production environment is also required due to health risks of isocyanates in pre-cured state.

Another universal synthetic adhesive/crosslinker that can be used as a crosslinker of starch and other bio-based adhesives is epoxy resin. Epoxy resins have been tested mainly for veneer gluing, e.g. in combination with polyvinyl acetate (PVAc) grafted starch adhesives. Epoxy groups form three-dimensional networks that provide good shear strength in both dry and humid conditions. ${ }^{\mathbf{1 5 2}}$

An innovative starch-based adhesive has been formulated by the addition of a silane coupling agent $\left(\mathrm{CH}_{2}=\mathrm{CH}-\mathrm{Si}\left(\mathrm{OC}_{2} \mathrm{H}_{5}\right)_{3}\right.$,
A-151, as a cross-linking agent), an olefin monomer (butyl acetate and vinyl acetate as a co-monomer) and hydrogen peroxide (as an oxidant). ${ }^{155}$ Fig. 16 shows the reaction pathway for the synthesis of this starch-based adhesive.

A starch/PVOH adhesive has been studied for birch veneers and the production conditions have been optimized accordingly. ${ }^{156}$ Hexamethoxymethylmelamine is found to be an effective crosslinker through transetherification reactions between the methoxy groups of the crosslinker and the hydroxyl groups of wood, starch and PVOH. Furthermore, latex is found to increase moisture resistance properties of starch. Crosslinking of starch with $\mathrm{PVOH}$ and the presence of latex also prevent microbial growth on the adhesive. Additives, such as citric acid, can be added to the starch/PVOH adhesives to potentially increase adhesion. ${ }^{157}$ Oxidized corn starch/PVA copolymers with 

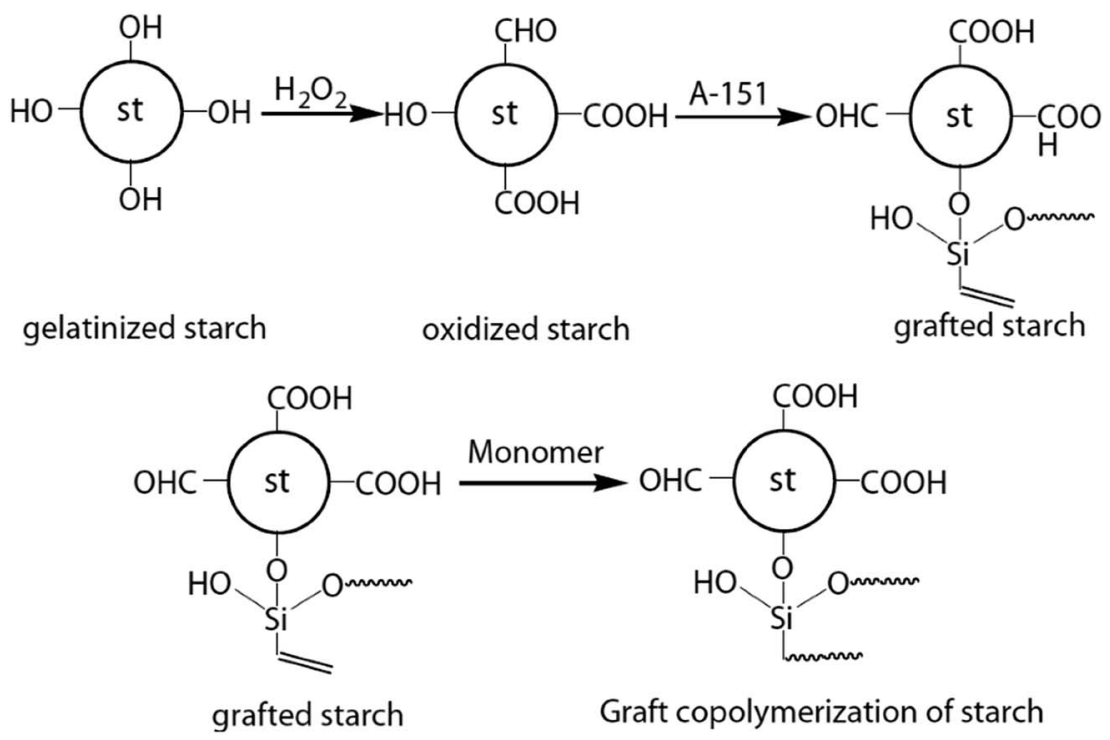

Fig. 16 Reaction pathway for the synthesis of starch-based adhesive (reproduced from ref. 155 with permission from Elsevier Ltd).

silane coupling agent have also given good results when used as solid wood adhesives. ${ }^{155}$ Sucrose molecules are relatively small compared with amylose and amylopectins of starch and extremely soluble in water. It has been proposed that sucrose can form hydrogen bonds with longer molecules of starch. Sucrose is caramelized at $160{ }^{\circ} \mathrm{C}$ and the bonding strength of the starch/sucrose adhesive for plywood is found to increase greatly above this temperature. Although sucrose increases the bonding strength for plywood when combined with starch, the best results are achieved when sucrose/tannin $(20 / 80 \mathrm{wt} \%)$ is combined with $\mathrm{NaOH}$ and tannin. $\mathrm{NaOH}$ and high temperature are supposed to catalyse starch and sucrose interactions. Starch can be denatured with $\mathrm{NaOH}$ to create less organized agglomerates that are more soluble in water and more easily penetrable to wood. ${ }^{158}$ Zheng et al. ${ }^{149}$ have studied the effects of starch heat pre-treatment at 70,80 and $90{ }^{\circ} \mathrm{C}$ on graft copolymerization reaction with vinyl acetate (VAc) and the performance of the resulting starch-based wood adhesive (SWA).

For low density particleboards, self-expanding cassava sour starch adhesive has been tested in a more recent study. Chitosan in propionic acid solution is added to the starch solution, before fibres and glycerol are added to the mixture. The panel properties of this preliminary study are promising. ${ }^{159}$

5.4.2. Additives to starch adhesives. As mentioned before, crosslinking and grafting of starch adhesives improve their properties. Thus, additional additives, such as nanoparticles and nanoclays, have been tested for starch-based adhesives. Silica nanoparticles and nanoclays have shown to increase the properties of polymer materials due to their small size, high surface energy and unsaturated chemical bonding on the surface. One example of this type of additive is montmorillonite (MMT), which is a nanolayered silicate belonging to the smectite clay family. It consists of two silicate layers and one aluminium layer between them, and this structure has the ability to swell and absorb water. Li et al. ${ }^{160}$ have studied the effects of adding MMT to their previously developed ${ }^{161}$ vinylacetate grafted corn starch adhesive. Adding MMT to starch up to $5 \%(\mathrm{w} / \mathrm{w})$ increases the shear strength of glued solid wood pieces (industrial standard of HG/T 272-1995) at room temperature and significantly increases thermal stability of the adhesive. Above 5\% MMT content, the properties of the adhesive start to decrease. These results are in line with previous findings, ${ }^{162}$ showing that nanoparticles can increase thermal stability, rheological properties, bonding strength, and water resistance when added to vinyl acetate grafted on corn starch.

Borate additives can form inter-chain linkages through a borate anion structure, and their introduction into starch has shown to increase its bonding ability and resistance to biodegradation. Cyano functions induced by these additives can form a donor-acceptor bond with the contacting phase and increase attachment of low surface energy polymers, such as starch. Derivatives of starch hydroxyl groups by cyanoethylation disrupt starch crystallites, causing starch to be easily dispersed in water. Nwokocha et al. (2011) ${ }^{163}$ have studied the performance of a cyanoethyl cassava starch adhesive by varying the amounts of cyano groups, solid content, $\mathrm{pH}$ and environmental moisture conditions. It is found that the adhesive strength is dependent on the degree of substitution. However, this cyanoethyl starch adhesive has poor moisture tolerance. ${ }^{163}$ Chen et al. ${ }^{164}$ use a silane coupling agent (KH570) as an additive to improve bonding performance and water stability of a starchbased wood adhesive. Sun et al. ${ }^{164}$ have proposed a new method of preparing a cassava starch-based wood adhesive with high performance using hydrogen peroxide, acrylamide, butyl acrylate (BA) and an organic siloxane as an oxidant, hard comonomer, soft co-monomer and crosslinking agent, respectively.

5.4.3. Other carbohydrates. Another carbohydrate worth mentioning, even if very little research has been done on it, is chitosan. Chitosan is obtained from chitin of shells by alkaline 
deacetylation, and it is the sole cationic polysaccharide. It is composed of mainly $(1,4)$ linked 2 -amino-2-deoxy- $\beta$-D-glucan and is soluble in acidic solutions but insoluble in alkaline solutions. Chitosan has been studied as a chitosan-phenolicslaccase system for veneer ${ }^{165}$ and in different formulations with glycerol on solid softwood pieces. ${ }^{166}$ Although the results promise adhesive possibilities for chitosan, a lot more work is required before conclusions can be made. ${ }^{166}$

\section{Outlooks and future propsects}

Bio-based adhesives provide a sustainable solution to indoor air quality and formaldehyde concerns. All adhesive raw materials discussed above can significantly reduce emissions (formaldehyde and VOCs) when replacing UF and MUF adhesives currently used in wood-based panel industry. At the same time, they can help the industry be less fossil-fuel dependent. However, bio-based adhesives suffer from several different issues that hinder their usage industrially. Be it availability for tannins, lack of adhesion for starches, poor water resistance for hydroxyl group enriched materials or viscosity for longmolecule chain polymers. Some of the main performance points are presented in Table 5 .

Tannin differs from other bio-adhesives. It provides good adhesion and can be used to make panels with higher moisture tolerance. Thus, its main advantage is that it does not need any reinforcement from synthetic petroleum-based adhesives, while suitable crosslinkers have already been identified at both lab and industrial scale. As tannin is highly reactive with short pot life, the purpose of new crosslinkers is to be less reactive than formaldehyde. Thus, hexamine, glyoxal, and tris(hydroxylmethyl)nitromethane are well suited for tannin-based adhesives, but rarely can be used for other bio-based adhesives for panel production. ${ }^{\mathbf{1 1 3}, \mathbf{1 1 8}}$ Even if extraction methods are developed, tannin extraction rates are not economically profitable for most wood species because tannins are not globally available for industrial use. Additionally, tannins have high viscosity, a dark colour and varying composition that depends on the species, growth conditions and time of harvesting. ${ }^{51}$ The modifications of tannins focus on decreasing viscosity for easier handling, increasing pot life and on creating better crosslinking. ${ }^{\mathbf{1 1 3}}$ In regions where tannin is readily available, tannin provides an industrially viable alternative for synthetic wood composite adhesives. For the other bio-based adhesives, a common problem seems to be exist based on all the research done so far: a lack of economically viable crosslinkers for biobased adhesives that would increase reactivity, mechanical properties, and humidity stability.

For lignin adhesives, the main problem is their extremely low reactivity, that leads to long pressing times and thus increased production costs in panel manufacturing. Pressing factors mentioned in the literature $\left(+30 \mathrm{~s} \mathrm{~mm}^{-1}\right)$ are three times higher than what is even considerable for lab scale particleboard testing. The industrial success in using these materials has therefore been small, though lignin has probably been the most intensely researched raw material for wood adhesive applications. ${ }^{89}$ Most of the research has been done on industrial lignin from pulping processes. Best results have been achieved by replacing phenol in $\mathrm{PF}$ resins. Industrial lignin has been used to replace up to $30 \%$ of synthetic phenol in the final resin without resulting in unsatisfactory properties of the produced adhesive. Increasing the percentage of industrial lignin in the final resin has been attempted through different modifications, such as methylolation, phenolation, demethylation and oxidation. ${ }^{72}$ Use of a combination of tannin/lignin to replace phenol and different crosslinkers to replace formaldehyde has also been reported in literature. ${ }^{\mathbf{1 0 0}}$ Crosslinking agents that have been and can be considered include aromatic aldehydes, glyoxal, furfuryl alcohol, caprolactam, glycol compounds and hexamine. ${ }^{99}$ Lignin from biorefinery processes have been less researched. These types of lignin are typically closer to their natural form than those from pulping processes. ${ }^{41}$ There are plenty unexplored modifications and ways to use them as adhesives. However, current methods are not strong enough to increase the reactivity of lignin to the level it needs to be so as to work as a wood adhesive. This is especially true for panels that require fast curing times, such as particleboards and fibreboards. Some effort has been put into turning biorefinery lignins into platform chemicals ${ }^{\mathbf{4 4}}$ but a cost-efficient way of doing this is still lacking.

Soy protein adhesives, on the other hand, have a promising future. Development of new crosslinkers and curing agents has enabled soy proteins to become commercially available in the North American market. Although they are so far only used in higher cost premium "green" panels, there is further potential due to the relatively low price and wide availability of soy protein as a by-product. They are environmentally friendly, relatively easy to handle, and have low pressing temperatures

Table 5 Comparison of different bio-based adhesives for wood panel industry

\begin{tabular}{llc}
\hline Biopolymer & Potential for adhesives & Crosslinker examples \\
\hline Lignin & $\begin{array}{l}\text { Available, low cost, low reactivity, requires modification, } \\
\text { low moisture resistance } \\
\text { Good adhesion, fast curing, high viscosity, good water resistance, }\end{array}$ & Aldehydes (e.g. glyoxal), MDI, tannin \\
Tannin & $\begin{array}{l}\text { poor geographical availability } \\
\text { Available, low pressing temperature, high viscosity, } \\
\text { Protein }\end{array}$ & $\begin{array}{l}\text { low water resistance (mostly), denaturation required } \\
\text { Medium cost, low reactivity, low water resistance, } \\
\text { modification/grafting required }\end{array}$
\end{tabular}


that enable lower production costs. ${ }^{137}$ However, the usage of soy adhesives has long been limited by their low water resistance, sensitivity to biological degradation and relatively low strength of the wood composites bound using them. ${ }^{14}$ For all proteinbased adhesives, controlling denaturation and creating good crosslinking in an economical way are the key parameters to create industrially viable solutions.

Starch-based adhesives provide many advantages for solid wood and plywood industries, as they are easy to handle, are low cost and have low formaldehyde emissions. However, the lack of reactivity, bonding strength, storage stability and water tolerance of starch-based adhesives makes them challenging when industrial board applications are considered. Proper modification combined with crosslinking is needed to reach the required bonding strength. So far, no economically viable bio-based crosslinkers are available on the market, and starch adhesives rely on synthetic crosslinkers, such as isocyanates and epoxides.

Developing good properties for bio-based adhesives other than tannin is challenging. Typically, adhesion is heavily hydrogen-bonding dependent, and the cross-linker needs to both increase adhesion and water resistance. Often there is a desire for the cross-linker to also be bio-based, but as of now, this is not possible mainly for economic reasons. Among the potential synthetic crosslinkers, isocyanates seem to be the most popular for bio-based applications close to commercialization. However, it should be noted and remembered that isocyanates can be used as panel adhesives on their own as well, even though they are expensive in Europe and require alterations in production due to safety issues. For panel production, when isocyanate-containing adhesives are used, special release agents are required to protect the pressing belts. Thus, it seems that in order to find industrially viable bio-based solutions, adhesive research needs to focus more on developing novel reactive crosslinkers.

The sustainable raw materials mentioned in this article belong to the most researched and well-known ones for biobased adhesives. Our knowledge on the modification of these natural materials has increased and new raw material options have emerged.

\section{Acknowledgements}

Venla Hemmilä and Stergios Adamopoulos would like to thank the Knowledge Foundation for financial support (project titled "New environment-friendly board materials", 2015-2019). The authors are grateful to all publishers (for example, Elsevier Ltd., American Chemical Society, Royal Society of Chemistry, Taylor \& Francis and PMDI) who permitted to use figures and tables from their publications.

\section{References}

1 Adhesives in the wood industry, ed. M. Dunky, 2003.

2 L. F. Zhao, Y. Liu, Z. D. Xu, Y. Z. Zhang, F. Zhao and S. B. Zhang, For. Stud. China, 2011, 13, 321-326.
3 P. Navarrete, Z. Kebbi, F. Michenot, J. Lemonon, C. Rogaume, E. Masson, Y. Rogaume and A. Pizzi, J. Adhes. Sci. Technol., 2013, 27, 748-762.

4 IARC, Press Release No. 153, 2004.

5 CARB, California Code of Regulations, section 9312093120.12, title 17, 2007.

6 N. A. Costa, J. Pereira, J. Ferra, P. Cruz, J. Martins, F. D. Magalhães, A. Mendes and L. H. Carvalho, Wood Sci. Technol., 2013, 47, 1261-1272.

7 S. Kim, H. J. Kim, H. S. Kim and H. H. Lee, Macromol. Mater. Eng., 2006, 291, 1027-1034.

8 M. Funk, R. Wimmer and S. Adamopoulos, Wood Mater. Sci. Eng., 2017, 12, 92-97.

9 A. Kumar, PhD, Universiti Malaysia Pahang, 2013.

10 A. Kumar, A. Gupta and K. V. Sharma, Holzforschung, 2015, 69, 199-205.

11 A. Kumar, K. Sharma, A. Gupta, J. Tywoniak and P. Hajek, Eur. J. Wood Wood Prod., 2017, 75, 203-213.

12 A. Kumar, A. Gupta, K. Sharma, M. Nasir and T. A. Khan, Int. J. Adhes. Adhes., 2013, 46, 34-39.

13 Congress Bill, H.R.2646 (107th) Congress of the United States of America, 2002.

14 K. Li, S. Peshkova and X. Geng, J. Am. Oil Chem. Soc., 2004, 81, 487-491.

15 S. H. Imam, C. Bilbao-Sainz, C. Bor-Sen, G. M. Glenn and W. J. Orts, J. Adhes. Sci. Technol., 2013, 27, 19721997.

16 T. M. Maloney, Modern particleboard and dry-process fiberboard manufacturing, Miller Freeman Pub., San Francisco, Calif. (USA), 1977.

17 Fiberboard manufacturing practices in the United States, ed. O. Suchsland and G. E. Woodson, 1987.

18 M. Baharoğlu, G. Nemli, B. Sarı, S. Bardak and N. Ayrılmış, Composites, Part B, 2012, 43, 2448-2451.

19 M. Böhm, M. Z. Salem and J. Srba, J. Hazard. Mater., 2012, 221, 68-79.

20 B. Sundin, B. Mansson and E. Endrody, Particleboard with different contents of releasable formaldehyde. A comparison on the board properties, including results from different formaldehyde tests, in Proceedings of the 21st Particleboard Symposium, Washington State University, Pullman, 1997, pp. 139-186.

21 R. Marutzky, E. Roffael and L. Ranta, Eur. J. Wood Wood Prod., 1979, 37, 303-307.

22 D. Corneau and R. Lovell, For. Prod. J., 2000, 50, 35.

23 J. J. Wolcott, W. K. Motter, N. K. Daisy, S. C. Tenhaeff and W. D. Detlefsen, For. Prod. J., 1996, 46, 62.

24 C. R. Frihart, J. M. Wescott, T. L. Chaffee and K. M. Gonner, For. Prod. J., 2012, 62, 551-558.

25 J. Xiong and Y. Zhang, Indoor Air, 2010, 20, 523-529.

26 C. Yu, D. Crump and R. Squire, Indoor Built Environ., 1999, 8, 287-292.

27 Formaldehyde release from wood products, ed. B. Meyer, B. K. Andrews and R. M. Reinhardt, American Chemical Society, 1986.

28 T. Salthammer, S. Mentese and R. Marutzky, Chem. Rev., 2010, 110, 2536-2572. 
29 T. Salthammer and S. Mentese, Chemosphere, 2008, 73, 1351-1356.

30 K. Eriksson, C. Heitner, D. Dimmel and J. Schmidt, Lignin Lignans, 2010, 495-520.

31 N.-E. E. Mansouri and J. Salvadó, Ind. Crops Prod., 2006, 24, 8-16.

32 H. Chung and N. R. Washburn, Green Mater., 2013, 1, 137160.

33 S. Laurichesse and L. Avérous, Prog. Polym. Sci., 2014, 39, 1266-1290.

34 A. Tejado, C. Pena, J. Labidi, J. Echeverria and I. Mondragon, Bioresour. Technol., 2007, 98, 1655-1663.

35 D. Watkins, M. Nuruddin, M. Hosur, A. Tcherbi-Narteh and S. Jeelani, J. Mater. Res. Technol., 2015, 4, 26-32.

36 M. V. Alonso, J. J. Rodríguez, M. Oliet, F. Rodríguez, J. García and M. A. Gilarranz, J. Appl. Polym. Sci., 2001, 82, 2661.

37 E. A. Capanema, M. Y. Balakshin, C. Chen-Loung, J. S. Gratzl and H. Gracz, Holzforschung, 2001, 55, 302.

38 C. G. da Silva, S. Grelier, F. Pichavant, E. Frollini and A. Castellan, Ind. Crops Prod., 2013, 42, 87-95.

39 N.-E. E. Mansouri and J. Salvadó, Ind. Crops Prod., 2006, 24, 8-16.

40 R. J. A. Gosselink, M. H. B. Snijder, A. Kranenbarg, E. R. P. Keijsers, E. de Jong and L. L. Stigsson, Ind. Crops Prod., 2004, 20, 191-203.

41 W. Zhang, Y. Ma, Y. Xu, C. Wang and F. Chu, Int. J. Adhes. Adhes., 2013, 40, 11-18.

42 J. H. Lora and W. G. Glasser, J. Polym. Environ., 2002, 10, 39.

43 P. Widsten and A. Kandelbauer, Biotechnol. Adv., 2008, 26, 379-386.

44 R. Ma, Y. Xu and X. Zhang, ChemSusChem, 2015, 8, 24-51.

45 E. Windeisen and G. Wegener, Lignin as Building Unit for Polymers-10.15, 2012, 2012.

46 E. T. N. Bisanda, W. O. Ogola and J. V. Tesha, Cem. Concr. Compos., 2003, 25, 593-598.

47 E. Aspé and K. Fernández, Ind. Crops Prod., 2011, 34, 838844.

48 P. Lan, A. Pizzi, G. Zhou Ding and N. Brosse, Ind. Crops Prod., 2012, 40, 13-20.

49 G. Vázquez, A. Pizzi, M. S. Freire, J. Santos, G. Antorrena and J. González-Álvarez, Wood Sci. Technol., 2013, 47, 523535.

50 M. Engstrom, M. Karonen, J. Ahern, N. Baert, B. Payré, H. Hoste and J.-P. Salminen, J. Agric. Food Chem., 2016, 64, 840-851.

51 R. M. Rowell, Handbook of Wood Chemistry and Wood Composites, CRC Press, 2005.

52 A. Pizzi, J. Adhes., 2009, 85, 57-68.

53 P. Nordqvist, N. Nordgren, F. Khabbaz and E. Malmström, Ind. Crops Prod., 2013, 44, 246-252.

54 A. R. Patel and K. P. Velikov, Curr. Opin. Colloid Interface Sci., 2014, 19, 450-458.

55 Z. Berk, Food and A. O. o. t. U. Nations, Technology of Production of Edible Flours and Protein Products from Soybeans, Food and Agriculture Organization of the United Nations, 1992.
56 C. R. Frihart and M. J. Birkeland, in Soy-Based Chemicals and Materials, ACS Publications, 2014, pp. 167-192.

57 R. Kumar, V. Choudhary, S. Mishra, I. K. Varma and B. Mattiason, Ind. Crops Prod., 2002, 16, 155-172.

58 C. Wang, J. Wu and G. M. Bernard, Ind. Crops Prod., 2014, 57, 124-131.

59 G. Qi, N. Li, D. Wang and S. X. Sun, J. Am. Oil Chem. Soc., 2012, 89, 301-312.

60 Y. H. Song, J. H. Seo, Y. S. Choi, D. H. Kim, B.-H. Choi and H. J. Cha, Int. J. Adhes. Adhes., 2016, 70, 260-264.

61 F. Y. García-Becerra, E. J. Acosta and D. Grant Allen, J. Am. Oil Chem. Soc., 2012, 89, 1315-1323.

62 H. Lei, A. Pizzi, P. Navarrete, S. Rigolet, A. Redl and A. Wagner, J. Adhes. Sci. Technol., 2010, 24, 1583-1596.

63 S. Khosravi, P. Nordqvist, F. Khabbaz and M. Johansson, Ind. Crops Prod., 2011, 34, 1509-1515.

64 C. E. Ferrández-García, J. Andreu-Rodríguez, M. T. Ferrández-García, M. Ferrández-Villena and T. García-Ortuño, BioResources, 2012, 7, 2012.

65 F. N. Emengo, S. E. R. Chukwu and J. Mozie, Int. J. Adhes. Adhes., 2002, 22, 93-100.

66 K. M. Salleh, R. Hashim, O. Sulaiman, S. Hiziroglu, W. Noor Aidawati Wan Nadhari, N. Abd Karim, N. Jumhuri and L. Z. P. Ang, J. Adhes. Sci. Technol., 2015, 29, 319-336.

67 N. Masina, Y. E. Choonara, P. Kumar, L. C. du Toit, M. Govender, S. Indermun and V. Pillay, Carbohydr. Polym., 2017, 157, 1226-1236.

68 Industrial uses of starch and its derivatives, (No. 664.22 R35), ed. J. A. Radley, Applied Science Publishers, London, 1976.

69 S. D'Amico, M. Hrabalova, U. Müller and E. Berghofer, Ind. Crops Prod., 2010, 31, 255-260.

70 B. Kaur, F. Ariffin, R. Bhat and A. A. Karim, Food Hydrocolloids, 2012, 26, 398-404.

71 A. Moubarik, N. Causse, T. Poumadere, A. Allal, A. Pizzi, F. Charrier and B. Charrier, J. Adhes. Sci. Technol., 2011, 25, 1701-1713.

72 L. Hu, H. Pan, Y. Zhou and M. Zhang, BioResources, 2011, 6, 1.

73 F. Ferdosian, Z. Pan, G. Gao and B. Zhao, Polymers, 2017, 9, 70.

74 D. Kai, M. J. Tan, P. L. Chee, Y. K. Chua, Y. L. Yap and X. J. Loh, Green Chem., 2016, 18, 1175-1200.

75 W. Zhao, L.-P. Xiao, G. Song, R.-C. Sun, L. He, S. Singh, B. A. Simmons and G. Cheng, Green Chem., 2017, 19, 3272-3281.

76 J.-L. Wen, S.-L. Sun, B.-L. Xue and R.-C. Sun, Materials, 2013, 6, 359-391.

77 B. Danielson and R. Simonson, J. Adhes. Sci. Technol., 1998, 12, 923.

78 R. K. Gothwal, M. K. Mohan and P. Ghosh, J. Sci. Ind. Res., 2010, 69, 390-395.

79 W. Zhang, Y. Ma, C. Wang, S. Li, M. Zhang and F. Chu, Ind. Crops Prod., 2013, 43, 326-333.

80 W.-J. Lee, K.-C. Chang and I. M. Tseng, J. Appl. Polym. Sci., 2012, 124, 4782-4788.

81 S. Yang, Y. Zhang, T. Q. Yuan and R. C. Sun, J. Appl. Polym. Sci., 2015, 132, 42493. 
82 S. Yang, J.-Q. Wu, Y. Zhang, T.-Q. Yuan and R.-C. Sun, J. Biobased Mater. Bioenergy, 2015, 9, 266-272.

83 S. Yang, J.-L. Wen, T.-Q. Yuan and R.-C. Sun, RSC Adv., 2014, 4, 57996-58004.

84 S. Zhao and M. M. Abu-Omar, ACS Sustainable Chem. Eng., 2017, 5, 5059-5066.

85 M. N. M. Ibrahim, N. Zakaria, C. S. Sipaut, O. Sulaiman and R. Hashim, Carbohydr. Polym., 2011, 86, 112-119.

86 P. Dongre, M. Driscoll, T. Amidon and B. Bujanovic, Energies, 2015, 8, 7897-7914.

87 J. Li and G. Gellerstedt, Ind. Crops Prod., 2008, 27, 175181.

88 K. Lundquist, Low-molecular weight lignin hydrolysis products, in Applied Polymer Symposium, 1976, vol. 28, pp. 1393-1407.

89 A. Pizzi, J. Adhes. Sci. Technol., 2006, 20, 829-846.

90 P. Benar, A. R. Gonçalves, D. Mandelli and U. Schuchardt, Bioresour. Technol., 1999, 68, 11-16.

91 G. Vázquez, J. González, S. Freire and G. Antorrena, Bioresour. Technol., 1997, 60, 191-198.

92 N. S. Çetin and N. Özmen, Int. J. Adhes. Adhes., 2002, 22, 477-480.

93 N. S. Çetin and N. Özmen, Int. J. Adhes. Adhes., 2002, 22, 481-486.

94 M. A. Khan, S. M. Ashraf and V. P. Malhotra, J. Appl. Polym. Sci., 2004, 92, 3514.

95 M. A. Khan, S. M. Ashraf and V. P. Malhotra, Int. J. Adhes. Adhes., 2004, 24, 485-493.

96 M. A. Khan and S. M. Ashraf, Indian J. Chem. Technol., 2006, 13, 347-352.

97 A. R. Gonçalves and P. Benar, Bioresour. Technol., 2001, 79, 103-111.

98 S. Kawai, M. Asukai, N. Ohya, K. Okita, T. Ito and H. Ohashi, FEMS Microbiol. Lett., 1999, 170, 51-57.

99 N.-e. El Mansouri, A. Pizzi and J. Salvadó, Eur. J. Wood Wood Prod., 2007, 65, 65-70.

100 P. Navarrete, A. Pizzi, S. Tapin-Lingua, B. BenjellounMlayah, H. Pasch, K. Rode, L. Delmotte and S. Rigolet, J. Adhes. Sci. Technol., 2012, 26, 1667-1684.

101 A. Tejado, G. Kortaberria, C. Peña, J. Labidi, J. M. Echeverria and I. Mondragon, Ind. Crops Prod., 2008, 27, 208-213.

102 P. Navarrete, A. Pizzi, S. Tapin-Lingua, B. BenjellounMlayah, H. Pasch, K. Rode, L. Delmotte and S. Rigolet, J. Adhes. Sci. Technol., 2012, 26, 1667-1684.

103 H. Lei, A. Pizzi and G. Du, J. Appl. Polym. Sci., 2008, 107, 203-209.

104 H. Mansouri, P. Navarrete, A. Pizzi, S. Tapin-Lingua, B. Benjelloun-Mlayah, H. Pasch and S. Rigolet, Eur. J. Wood Wood Prod., 2011, 69, 221-229.

105 D. Stewart, Ind. Crops Prod., 2008, 27, 202-207.

106 C. Felby, L. G. Thygesen, A. Sanadi and S. Barsberg, Ind. Crops Prod., 2004, 20, 181-189.

107 M. Nasir, A. Gupta, M. D. H. Beg, G. K. Chua and A. Kumar, Int. J. Adhes. Adhes., 2013, 44, 99-104.

108 M. Nasir, A. Gupta, M. Beg, G. K. Chua, M. Jawaid, A. Kumar and T. A. Khan, BioResources, 2013, 8, 3599-3608.
109 Y. Zhang, J.-Q. Wu, H. Li, T.-Q. Yuan, Y.-Y. Wang and R.-C. Sun, ACS Sustainable Chem. Eng., 2017, DOI: 10.1021/acssuschemeng.7b01485.

110 A. Pizzi, in Handbook of Adhesive Technology, Revised and Expanded, CRC Press, 2003.

111 S. Spina, X. Zhou, C. Segovia, A. Pizzi, M. Romagnoli, S. Giovando, H. Pasch, K. Rode and L. Delmotte, Int. Wood Prod. J., 2013, 4, 95-100.

112 A. Moubarik, A. Allal, A. Pizzi, F. Charrier and B. Charrier, Eur. J. Wood Wood Prod., 2010, 68(4), 427-433.

113 A. Pizzi, J. Adhes., 2009, 85, 57.

114 C. Peña, K. Caba, A. Retegi, C. Ocando, J. Labidi, J. Echeverria and I. Mondragon, J. Therm. Anal. Calorim., 2009, 96, 515.

115 Z. Osman, J. Therm. Anal. Calorim., 2012, 107, 709.

116 S. Jahanshaei, T. Tabarsa and J. Asghari, Pigm. Resin Technol., 2012, 41, 296-301.

117 C. Li, W. Wang, Y. Mu, J. Zhang, S. Zhang, J. Li and W. Zhang, J. Polym. Environ., 2017, 1-13.

118 G. Vázquez, J. Santos, M. Freire, G. Antorrena and J. González-Álvarez, J. Therm. Anal. Calorim., 2012, 108, 605.

119 M. Basso, A. Pizzi, J. P. Maris, L. Delmotte, B. Colin and Y. Rogaume, Ind. Crops Prod., 2017, 95, 621-631.

120 F. Pichelin, C. Kamoun and A. Pizzi, Holz Roh-Werkst., 1999, 57, 305.

121 J. Valenzuela, E. von Leyser, A. Pizzi, C. Westermeyer and B. Gorrini, Eur. J. Wood Wood Prod., 2012, 70, 735-740.

122 A. Trosa and A. Pizzi, Holz Roh-Werkst., 2001, 59, 266.

123 D. S. Patel, S. D. Toliwal and J. V. Patel, J. Adhes. Sci. Technol., 2012, 26, 2217-2227.

124 S. Omura, Y. Kawazoe and D. Uemura, Int. J. Adhes. Adhes., 2017, 74, 35-39.

125 D. Vnučec, A. Kutnar and A. Goršek, J. Adhes. Sci. Technol., 2017, 31, 910-931.

126 K. S. Liu, Soybeans: Chemistry, Technology and Utilization, Springer, 1997.

127 J. M. Wescott, C. R. Frihart and A. E. Traska, J. Adhes. Sci. Technol., 2006, 20, 859-873.

128 R. M. Rowell, F. Caldeira and J. K. Rowell, Sustainable development in the forest products industry, Universidade Fernando Pesoa, Portugal, 2010.

129 J. M. Wescott and C. R. Frihart, Competitive soybean flour/ phenol-formaldehyde adhesives for oriented strandboard, 2004.

130 X. Mo, J. Hu, X. S. Sun and J. A. Ratto, Ind. Crops Prod., 2001, 14, 1-9.

131 Y. Wang, D. Wang and X. S. Sun, J. Am. Oil Chem. Soc., 2005, 82, 357-363.

132 X. Sun and K. Bian, J. Am. Oil Chem. Soc., 1999, 76, 977.

133 W. Huang and X. Sun, J. Am. Oil Chem. Soc., 2000, 77, 101.

134 Z. Zhong, X. Susan Sun, X. Fang and J. A. Ratto, Int. J. Adhes. Adhes., 2002, 22, 267-272.

135 L. Lorenz, C. R. Frihart and J. M. Wescott, Presented in part at the Wood adhesives 2005, San Diego, California, USA, 2005.

136 K. Li and Y. Liu, Int. J. Adhes. Adhes., 2007, 27, 59-67.

137 K. Gu and K. Li, J. Am. Oil Chem. Soc., 2011, 88, 673-679. 
138 A. I. Hamarneh, H. J. Heeres, A. A. Broekhuis, K. A. Sjollema, Y. Zhang and F. Picchioni, Int. J. Adhes. Adhes., 2010, 30, 626-635.

139 H. N. Cheng, C. Ford, M. K. Dowd and Z. He, Int. J. Adhes. Adhes., 2016, 68, 156-160.

140 P. Nordqvist, F. Khabbaz and E. Malmström, Int. J. Adhes. Adhes., 2010, 30(2), 72-79.

141 S. Pradyawong, G. Qi, N. Li, X. S. Sun and D. Wang, Int. J. Adhes. Adhes., 2017, 75, 66-73.

142 H. Liu, C. Li and X. S. Sun, Int. J. Adhes. Adhes., 2017, 73, 6674.

143 L. F. Lorenz, A. H. Conner and A. W. Christiansen, For. Prod. J., 1999, 49, 73.

144 D.-B. Fan, T.-F. Qin and F.-X. Chu, J. Adhes. Sci. Technol., 2011, 25, 323-333.

145 Y. Jang, J. Huang and K. Li, Int. J. Adhes. Adhes., 2011, 31, 754-759.

146 C. Yuan, M. Chen, J. Luo, X. Li, Q. Gao and J. Li, Carbohydr. Polym., 2017, 169, 417-425.

147 D. Liu, H. Chen, P. R. Chang, Q. Wu, K. Li and L. Guan, Bioresour. Technol., 2010, 101, 6235-6241.

148 L. Cheng, H. Guo, Z. Gu, Z. Li and Y. Hong, Int. J. Adhes. Adhes., 2017, 72, 92-97.

149 X. Zheng, L. Cheng, Z. Gu, Y. Hong, Z. Li and C. Li, Int. J. Biol. Macromol., 2017, 96, 11-18.

150 S. H. Imam, L. Mao, L. Chen and R. V. Greene, Starch/ Staerke, 1999, 51, 225-229.

151 Z. Qiao, J. Gu, S. Lv, J. Cao, H. Tan and Y. Zhang, J. Adhes. Sci. Technol., 2015, 29, 1368-1381.

152 Y. Nie, X. Tian, Y. Liu, K. Wu and J. Wang, Polym. Compos., 2013, 34, 77.

153 Y. Wang, H. Xiong, Z. Wang and L. Chen, Int. J. Biol. Macromol., 2017, 103, 819-828.

154 H. Tan, Y. Zhang and X. Weng, Procedia Eng., 2011, 15, 1171-1175.

155 Y. Zhang, L. Ding, J. Gu, H. Tan and L. Zhu, Carbohydr. Polym., 2015, 115, 32-37.

156 S. H. Imam, S. H. Gordon, L. Mao and L. Chen, Polym. Degrad. Stab., 2001, 73, 529-533.

157 W. Sridach, S. Jonjankiat and T. Wittaya, J. Adhes. Sci. Technol., 2013, 27, 1727-1738.

158 G. Tondi, S. Wieland, T. Wimmer, T. Schnabel and A. Petutschnigg, Eur. J. Wood Wood Prod., 2012, 70, 271-278.
159 S. Monteiro, J. Martins, F. D. Magalhães and L. Carvalho, Polymers, 2016, 8, 354.

160 Z. Li, J. Wang, C. Li, Z. Gu, L. Cheng and Y. Hong, Carbohydr. Polym., 2015, 115, 394-400.

161 Z. Li, J. Wang, L. Cheng, Z. Gu, Y. Hong and A. Kowalczyk, Carbohydr. Polym., 2014, 99, 579-583.

162 Z. Wang, Z. Gu, Y. Hong, L. Cheng and Z. Li, Carbohydr. Polym., 2011, 86, 72-76.

163 L. M. Nwokocha, J. Adhes. Sci. Technol., 2011, 25, 893-902.

164 L. Chen, Y. Wang, P. Fei, W. Jin, H. Xiong and Z. Wang, Int. J. Biol. Macromol., 2017, 104A, 137-144.

165 S. Peshkova and K. Li, J. Biotechnol., 2003, 102, 199-207.

166 A. K. Patel, P. Michaud, E. Petit, H. de Baynast, M. Grédiac and J. D. Mathias, J. Appl. Polym. Sci., 2013, 127, 5014-5021.

167 D. Theng, N.-E. El Mansouri, G. Arbat Pujolràs, B. Ngo, M. Delgado Aguilar, M. À. Pèlach Serra, P. Fullana i Palmer and P. Mutjé Pujol, BioResources, 2017, 12, 23792393.

168 J. Cui, X. Lu, X. Zhou, L. Chrusciel, Y. Deng, H. Zhou, S. Zhu and N. Brosse, Ann. For. Sci., 2015, 72, 27-32.

169 F. Santiago-Medina, G. Foyer, A. Pizzi, S. Caillol and L. Delmotte, Int. J. Adhes. Adhes., 2016, 70, 239-248.

170 Z. Xiao, Y. Li, X. Wu, G. Qi, N. Li, K. Zhang, D. Wang and X. S. Sun, Ind. Crops Prod., 2013, 50, 501-509.

171 R. Tupciauskas, J. Gravitis, J. Abolins, A. Veveris, M. Andzs, T. Liitia and T. Tamminen, Holzforschung, 2017, 71(7-8), $555-561$.

172 U. H. B. Abdullah and A. Pizzi, Eur. J. Wood Wood Prod., 2013, 71, 131-132.

173 M. F. M. Yusof, R. Hashim, A. A. Tajuddin, S. Bauk and O. Sulaiman, Ind. Crops Prod., 2017, 95, 467-474.

174 D. Efhamisisi, M.-F. Thevenon, Y. Hamzeh, A.-N. Karimi, A. Pizzi and K. Pourtahmasi, ACS Sustainable Chem. Eng., 2016, 4, 2734-2740.

175 R. Widyorini, P. A. Nugraha, M. Z. A. Rahman and T. A. Prayitno, BioResources, 2016, 11, 4526-4535.

176 J. Fitzken Da Vinci M. Niro, M. Kyriazopoulos, S. Bianchi, I. Mayer, D. A. Eusebio, J. R. Arboleda, M. Lanuzo and F. Pichelin, Int. Wood Prod. J., 2016, 7(4), 208-214.

177 J. Podschun, A. Stücker, R. I. Buchholz, M. Heitmann, A. Schreiber, B. Saake and R. Lehnen, Ind. Eng. Chem. Res., 2016, 55, 5231-5237.

178 Z. He and H. N. Cheng, J. Adhes. Sci. Technol., 2017, 1-10. 